\title{
EL ESPACIO PÚBLICO COMO EJE DE LA SEGURIDAD Transformaciones urbanas y políticas públicas
}

\author{
Carla Miranda Chiguindo \\ Universidad Autónoma del Estado de México, Facultad de Planeación Urbana y Regional \\ Director: Juan José Gutiérrez Chaparro \\ carla_chiguindo@hotmail.com
}

\section{RESUMEN}

Debido a la reciente crisis de violencia en México, se han planteado diferentes rutas para enfrentar dicha problemática. Una de las estrategias más recurridas localmente es la creación o recuperación de espacios públicos en barrios con altos índices delictivos. Sin embargo, la inseguridad no solo no disminuye, sino que los indicadores apuntan a un repunte de la violencia. El artículo plantea el caso Barrios Tradicionales, en Toluca, México. La metodología se basa en el análisis de tres dimensiones: diseño urbano; función comunitaria y social; $y$ análisis territorial. A partir de ello, se reconoce que sí hay efectos de las intervenciones, pero son parciales y temporales; que los criterios políticos determinan, más que los urbanísticos, el éxito o fracaso de una política pública; y que no se considera a la población en la toma de decisiones, por lo que es indispensable replantear las políticas públicas de seguridad y urbanas.

Palabras clave: espacio público, seguridad ciudadana, intervenciones urbanas, políticas públicas

\begin{abstract}
Due to the recent crisis of violence in Mexico, different policies have been proposed to confront this problem. One of the strategies most used locally is the creation or recovery of public spaces in neighborhoods with high crime rates. However, insecurity not only does not decrease, but the indicators point to a rebound in violence. The article presents the Barrios Tradicionales case, in Toluca, Mexico. The methodology is based on the analysis of three dimensions: urban design; community and social function; and territorial analysis. From this, it is recognized that there are som effects improving security, of the interventions, but those are partial and temporal; that political criteria determines, more than urban planning, the success or failure of a public policy; and, finally, people is not considered in decision making, which decreases the possibility of achieving true improvements. So, it is essential to rethink public and urban security policies.
\end{abstract}

Key words: public space, citizen security, interventions, public policies. 


\section{INTRODUCCIÓN}

El inicio del siglo XXI en México ha sido marcado por una crisis de violencia e inseguridad en diferentes zonas y regiones del país, que ha definido la agenda política del país y puesto sobre la mesa la necesidad de replantear las políticas públicas de seguridad. Se han planteado nuevas políticas públicas dirigidas a la recuperación de los entornos violentos e inseguros, y se han trazado rutas paralelas para reconstruir condiciones de seguridad. Una de las estrategias más recurridas en el ámbito local es la recuperación, creación o rehabilitación de espacios públicos en colonias o barrios con altos índices de conflictividad, violencia y delincuencia.

El espacio público ha sido objeto de intervenciones que buscan convertirlo en el eje de la convivencia, a fin de resarcir el daño al tejido social que se observa en contextos urbanos específicos. Esto ha llevado a que, inspirados generalmente en experiencias exitosas en otras partes del mundo, plazas, paseos, bajopuentes, parques, sean remodelados, equipados y acondicionados para convertirse en espacios seguros de convivencia.

Sin embargo, los resultados no son alentadores. La evaluación de los resultados se ha realizado a partir de indicadores eminentemente cuantitativos y tradicionales, como índices delictivos. Estos muestran que la inseguridad no solo no ha ido a la baja, sino que se han registrado repuntes importantes en el más notorio y significativo: número de homicidios dolosos. Con esta óptica, puede presumirse que la política pública ha fracasado y por tanto hay razones para que sea suspendida.

Se presenta en el artículo el estudio de caso de Barrios Tradicionales, un barrio altamente conflictivo en la ciudad de Toluca, en el cual se ha intervenido el espacio público con el fin de mejorar las condiciones de seguridad, y a partir de políticas públicas urbanas y de seguridad. La metodología se basada en el análisis de tres dimensiones: diseño urbano; función comunitaria y social; y análisis territorial. A partir de estos tres aspectos se determinó que si el espacio público aporta a la construcción de condiciones de seguridad aunque de forma parcial; que es frecuente que los criterios políticos determinen, más que los urbanísticos, el éxito o fracaso de una política pública de seguridad y urbana; que si se considera a la población en la toma de decisiones, las políticas de seguridad tendrían resultados diferentes; y que es indispensable replantear la forma de evaluación de las políticas públicas de seguridad y urbanas, desde una postura más humana y comprehensiva de la realidad social.

Se busca responder a la pregunta siguiente ¿La mejora de los espacios públicos, a partir de políticas públicas enfocadas en la prevención, logra un efecto en las condiciones de seguridad ciudadana del entorno? ¿existe conexión entre las acciones de mejora de los espacios públicos, las políticas urbanas, los objetivos de mejora en la seguridad y los resultados obtenidos?; en todo caso, ¿cómo se da esta relación?

La investigación se aborda desde la vinculación que existe entre la disciplina del urbanismo y la importancia de los espacios públicos en la ciudad; el enfoque de la seguridad ciudadana, concepto relativamente nuevo que alude a una forma de interpretar la seguridad en términos del ejercicio de derechos y libertades, con una perspectiva amplia de la acción del Estado, con la prevención como centro de la política; así como el reconocimiento de la importancia de la influencia política del Estado, a través de las políticas públicas tanto urbanas como de seguridad. La relación es abordada tanto teórica como empíricamente, pues hoy en día se han documentado importantes experiencias en el mundo sobre estrategias urbanas dirigidas a mejorar condiciones de seguridad dirigidas por el Estado.

El análisis se realiza a partir de Políticas urbanas y de seguridad, a nivel federal y municipal, para tratar de encontrar las concepciones del espacio público como generador o elemento clave para mejorar la seguridad. Especialmente, a partir de la política nacional de prevención social de la violencia y delincuencia, que tuvo incidencia, a través de recursos federales, en demarcaciones específicas en todo el país, algunas de ellas ubicadas en el Estado de México y en el municipio de Toluca. Así también, la experiencia en seguridad ciudadana y prevención, en diferentes contextos internacionales, ha sido una fuerte influencia para definir acciones en la materia en nuestro país. Por ello, se desarrolla una explicación a partir de experiencias internacionales y nacionales sobre la forma en que, desde diferentes problemáticas de inseguridad y en contextos sociales diferentes, se ha incidido para mejorar la seguridad de las personas a partir de crear, rehabilitar o mejorar el espacio público. 


\section{EL ESPACIO PÚBLICO Y SU FUNCIÓN}

El espacio público intervenido es abordado desde estas perspectivas, en tanto se busca que su creación o mejoramiento incida en la mejora de condiciones de seguridad ciudadana. El marco teórico que se construye retoma, en primer lugar, los enfoques teóricos más importantes del urbanismo, que han tocado o retomado su influencia sobre la seguridad urbana. En segundo lugar, aborda el nuevo enfoque de la seguridad ciudadana, que permite concebir este desde una perspectiva que supera la visión policial del Estado, y que remite a que la construcción de condiciones de seguridad pasa por estrategias urbanísticas y la acción del estado, junto con la sociedad, actuando en el espacio público. Finalmente, se construye teóricamente el papel del Estado y la manifestación de su acción a través de políticas públicas que con enfoque de seguridad inciden en el espacio urbano para transformarlo. Estas son las tres grandes líneas teóricas que confluyen en el tema de la investigación que se presenta y que se desarrollan a continuación.

El espacio público es "un concepto jurídico: un espacio sometido a una regulación específica por parte de la Administración pública, propietaria o que posee la facultad de dominio del suelo y que garantiza su accesibilidad a todos y fija las condiciones de su utilización y de instalación de actividades" (Di Siena, 2013). Sin embargo, las definiciones a partir de la concepción de ciudad, de ciudadanía y de ser humano, superan la perspectiva jurídica. Los espacios públicos son áreas de suelo donde la gente lleva fuera sus actividades funcionales y rituales que unen a la comunidad, ya sea en las rutinas de la vida diaria o en sus festividades periódicas; o, es el escenario sobre el cual el drama de la vida de la comunidad se desarrolla (Carr, 1992).

También pueden ser entendidos como todas las partes de la "fábrica urbana", con acceso físico y visual. Asimismo, lo extiende desde las calles, parques y cuadras o manzanas de una localidad o una ciudad, hacia los edificios que lo conforman, delimitan y delinean (Tibbalds, 1992).

Pero la importancia del espacio público ha elevada por los estudios académicos y de la línea del urbanismo culturalista, debido a la función social que desempeña en el entramado urbano. Según Jordi Borja (1998), el espacio público, incluyendo la infraestructura y los equipamientos, puede ser un importante mecanismo de redistribución e integración sociales. Depende de cómo se diseñen o de cómo se conciban las grandes operaciones urbanas. Es decir, un espacio público puede propiciar la integración social bajo la perspectiva de que es el espacio en el que cualquiera puede estar, y donde todos tienen los mismos derechos de ser, de estar y de usar. En ese mismo tenor, el espacio público es el lugar por excelencia donde se establecen relaciones, de acuerdos y conciliaciones, donde la convivencia social se ejerce en su plenitud.

El espacio público se concibe cada vez más como un lugar común de relación, identificación, encuentro y actividades entre diferentes miembros de la sociedad. Lo público se entiende como el espacio de todos, donde conviven la diferencia y la diversidad, y todos aprenden a vivir juntos y a compartir valores tales como el respeto, la solidaridad y la tolerancia (Ramírez Kuri, 2009). El espacio público permite que, a pesar de las diferencias entre los miembros de la sociedad, existan elementos de unión y cohesión que puedan generar una comunidad vinculada a partir del interés y participación en torno a los temas compartidos de quienes viven juntos.

La cohesión social se manifiesta en la ocupación de los espacios públicos y en las interrelaciones que de esta ocupación se generan. Se puede establecer entonces que cuando el tejido social se fragmenta, o se debilita, se observa el abandono de los espacios públicos, lo cual provocará que se pierda el control del territorio, y que quien ocupe el espacio público sea visto como "extraño", como "el otro", incluso como "el enemigo". Con ello, se empieza a construir una percepción negativa de la seguridad. Surge entonces el conflicto de la ciudad y los espacios públicos. Carrión alude a que la ciudad en construcción, va perdiendo espacios públicos y cívicos, se generaliza la urbanización privada-amurallada que segrega; se reduce el espacio de la ciudad y, en particular el espacio público,

\section{EL ESPACIO PÚBLICO Y SU EFECTO SOCIAL}

Como se ha mencionado, el espacio público tiene un papel primordial en el entramado urbano, por las dimensiones que abarca y por la influencia en las relaciones urbanas. Como apunta Jordi Borja (citado por DiSienna, 2009), el espacio público se puede valorar por la intensidad y la calidad de las relaciones sociales que facilita, por su capacidad de mezclar grupos y comportamientos, de estimular la identificación simbólica, la expresión y la integración cultural. Además, apunta el mismo autor, es en el espacio público donde se pueden ejercer a plenitud los derechos ciudadanos y se concentran las interacciones humanas más genuinas. 
La apropiación de los espacios públicos es abordada desde variadas perspectivas y explicada con diferentes definiciones para intentar comprender este fenómeno. Se trata acerca de cómo las personas en las ciudades toman o se apropian de espacios públicos para realizar actividades de tipo cultural o deportivo, así como distintas manifestaciones de prácticas individuales o colectivas, en lugares o espacios públicos donde no necesariamente han sido diseñados para la realización de esas actividades, sin embargo, las personas le van dando ese uso y se van apropiando de dicho lugar. Fonseca (2014) retoma a Vidal y Urrútia (2005), para explicar que desde el punto de vista de la psicología, el concepto de apropiación es visto como una experiencia generalizada del ser humano que se concreta con significados de la realidad, es decir, se crea una construcción socio-histórica de esta realidad, apoyándose en la idea de que la praxis humana se convierte en algo instrumental y, a la vez, social para que de ésta surja la conciencia.

La definición de espacio público, así como los fenómenos que ahí se desarrollan, en este caso la apropiación, dan una visión de la importancia y del papel que éstos tienen para la sociedad, en especial la sociedad urbana. Los usos y las actividades que ahí se practican permiten determinar aspectos como el grado de integración social, los alcances de sentido de pertenencia, la capacidad de apropiación de lo público, los niveles de democracia obtenidos en las distintas comunidades o barrios de una ciudad (Torres, 2009). La conquista de los espacios públicos es donde el territorio se percibe como una historia personal y colectiva, donde la población se descubre y representa a sí misma, los proyectos compartidos posibilitan la cooperación en la construcción de un sentido de pertenencia territorial y espacial (Segovia, Jordan, 2005).

De esta forma, el tema que atiende la presente investigación alude a la relación existente entre la forma en que la perspectiva urbanística hoy en día es una aportación necesaria a la forma en que se buscan construir condiciones de seguridad que permitan hacer viable el derecho a la ciudad. La evolución de las propuestas teóricas del urbanismo plantea posturas ahora concordantes al Estado moderno de tipo neoliberal o de neobienestar, que busca ampliar la participación ciudadana, se reconoce en democracia y que acepta la prevalencia de la decisión política incluso por encima de lo técnico. De hecho, hoy se involucra a las discusiones sobre la ciudad el tema de los derechos de las personas a hacer un uso pleno de la misma.

La seguridad, entendida en una perspectiva amplia y multidimensional, comprende hoy no sólo perspectivas policiales sino que pone atención en buscar condiciones en las cuales las personas puedan ejercer a plenitud sus derechos y libertades. Reconoce que el espacio natural para ello es el espacio público, y este, desde la perspectiva urbanística, pero también de la seguridad, se convierte en el centro de la atención. En concordancia, el espacio público (que por naturaleza es democrático), es el lugar donde se ejerce el derecho a la ciudad, y que debe ser preservado en la medida de lo posible de condiciones que lo hagan inseguro.

Esta preservación se retoma en las políticas públicas, que confluyen en el espacio público como transformadoras del espacio (políticas urbanas) pero también como directrices de estrategias de seguridad (políticas de seguridad). Se plantea entonces la acción estatal, como elemento determinante en la definición de lo que se hace en los entornos de la ciudad, limitando la acción del urbanimo y dirigiendo los mecanismos securizantes, tal como plantea Sánchez de Madariaga (2008).

En el tema de la política pública se observa una confluencia de la política pública de seguridad y la política pública urbana, en tanto una buena política urbana puede ser de hecho una parte importante de la política pública de seguridad; mientras que una política de seguridad ciudadana incluye, necesariamente, elementos de política pública urbana. Así lo han demostrado experiencias en diferentes partes del mundo, en las que se ha demostrado que a partir de intervenciones urbanas se transforma el panorama de seguridad en que viven las personas, convirtiéndose en referentes y ejemplo de cómo planteamientos teóricos multidisciplinarios influyan en el diseño de políticas públicas y se logre una gran incidencia en la vida social.

\section{LA INTERVENCION EN EL ESPACIO PÚBLICO: EL MACRO-MURAL URBANO DE PALMITAS}

El municipio de Pachuca, en el estado de Hidalgo, es uno de los beneficiarios de los recursos federales del Programa Nacional de Prevención Social de la Violencia y la Delincuencia, parte de los cuales se destinaron a acciones relativas al rescate de barrios con altos niveles de incidencia delictiva, marginación urbana y pobreza. La génesis del proyecto es relevante, pues el proyecto original se realizaría en el barrio ubicado en el cerro de Cubitos. Sin embargo, se determinó que finalmente la ubicación del proyecto sería en el cerro de Palmitas, que también forma parte de la zona de barrios altos de Pachuca.

El gobierno emprendió el proyecto en Palmitas en 2014 con un presupuesto de cinco millones de pesos. El colectivo Germen Crew fue convocado para la realización de este proyecto, y su papel fundamental, además 
de la concepción creativa del proyecto, fue la integración comunitaria para generar procesos que construyan cohesión social, impacto buscado en proyectos similares en el mundo. La elaboración del Macro-mural tuvo una duración de quince meses y la inversión fue de 7500 millones de pesos. Fue inaugurado el 31 de agosto de 2015.

El mural comprende 209 casas habitación que fueron pintadas en una área de $20000 \mathrm{~m}^{2}$, con 190 colores. Se pintó bajo la técnica de graffiti, y de acuerdo con las fuentes oficiales, en la obra participaron directamente mil 800 habitantes, y se beneficiaron a más de 450 familias. Para su realización, se contó con patrocinio privado, a través de la colaboración de la empresa de pinturas COMEX, el colectivo pintó primero de blanco toda la colonia. Luego se aplicó la distribución del color, después de agregaron detalles únicos que solo se podrán apreciar al adentrarse a las calles y callejones del barrio. El concepto de la obra fue plasmar el sobrenombre de Pachuca "La Bella Airosa", y sí, a lo lejos los colores se ven como olas de aire.

De acuerdo con la Secretaria de Planeación y Evaluación del Ayuntamiento de Pachuca, la incidencia delictiva disminuyó durante el desarrollo del mural. De acuerdo con sus estadísticas de 56 accidentes registrados en 2012, se pasó a 44 en 2013, 34 en 2014 y solo 12 en el periodo enero-junio de 2015; en tanto que los robos o asaltos pasaron de 42 a 38, a 31 y a 11, respectivamente para cada año mencionado. Las faltas administrativas pasaron de 48 en 2012 a 40 en 2013, 28 en 2014 y siete en el primer semestre de este año; mientras que los incendios fueron uno, cuatro, cuatro y uno, respectivamente.

\section{POLITICAS PUBLICAS DE SEGURIDAD Y URBANAS EN EL ESPACIO PÚBLICO}

Al atender políticas públicas en materia de seguridad, en particular, uno de los temas que debe considerarse siempre es la complejidad que sobre el tema impone el diseño institucional federalista de México. En materia de seguridad, cada ámbito (federal, estatal y municipal) tiene delimitadas sus competencias, pero hay un espacio para la coordinación entre las instancias responsables de la seguridad, a través de un complejo entramada institucional, normativo, político y administrativo. Si bien, en estricto sentido, se refiere a la función del estado entendida como Seguridad Pública, en general todas las acciones que no sean estrictamente policiales pero que correspondan a un tema de seguridad se verán influidas por la complejidad en la operación de las políticas justamente por este diseño institucional.

Por parte de los niveles locales, estatales y municipales, es notable que las políticas en materia de seguridad implican una fuerte influencia y dirección de las políticas federales vigentes, lo cual fue también un criterio para determinar el periodo temporal de la investigación, pues es un lapso en el que coinciden en todos los ámbitos de competencia de los gobiernos a generar diversos tipos de programas y proyectos dirigidos a los espacios públicos (mejora, regeneración, rescate, recuperación, etc.), en aras de la seguridad, la convivencia, la cohesión social, la recuperación del tejido social, entre otros aspectos.

Se promueve, a partir de las ideas relacionadas anteriormente, una nueva forma de concebir y entender, por un lado, la inseguridad como un fenómeno social de origen multifactorial y multidimensional, para cuya atención se requieren, en la misma medida, estrategias que atiendan diferentes niveles y dimensiones en las que se encuentran los factores de riesgo (teoría epidemiológica). Las respuestas a las condiciones prevalecientes de inseguridad se verán plasmadas en políticas públicas de seguridad con carácter preventivo y de seguridad ciudadana.

El siguiente cuadro reúne los instrumentos de política pública que actúan sobre el espacio público, pues a partir de 2006, el espacio público ya no es sólo un elemento urbano de conectividad, recreación, identidad, u otras funciones; sino un escenario y un componente de las condiciones de seguridad/inseguridad en las ciudades del país. A nivel municipal, en el caso de Toluca, Estado de México, se encuentran la confluencia de los siguientes instrumentos:

\section{Cuadro No. 2 \\ Políticas públicas de seguridad, prevención y espacios públicos 2006-2016}

\begin{tabular}{|l|l|l|}
\hline Ámbito & Política pública/Programa/Instancia & Año/Vigencia \\
\hline Federal & Plan Nacional de Desarrollo & $2007-2012$ \\
& Programa Limpiemos México & $2008-2012$ \\
& Plan Nacional de Desarrollo & $2013-2018$ \\
\hline
\end{tabular}




\begin{tabular}{|l|l|l|}
\hline & $\begin{array}{l}\text { Programa Nacional de Prevención Social de la Violencia } \\
\text { y la Delincuencia - SeGob }\end{array}$ & $2014-2018$ \\
\hline \multirow{2}{*}{ Estatal } & $\begin{array}{l}\text { Plan de Desarrollo del Estado de México } \\
\text { Plan Estatal de Desarrollo Urbano } \\
\text { Programa de Seguridad del Estado de México }\end{array}$ & $2011-2017$ \\
\hline & Programa de Prevención Social del delito & NE \\
\hline Municipal & Plan de Desarrollo Municipal & NE \\
\hline & Plan de Desarrollo Municipal & $2013-2015$, \\
& Plan de Desarrollo Urbano Municipal & $2016-2018$ \\
\hline & Programa Ecozona & 2013 \\
\hline & Programa Municipal de Seguridad & 2015 \\
\hline
\end{tabular}

Fuente: Elaboración propia

NE: No existe/No se encontró

\section{Plan Nacional de Desarrollo 2013-2018}

El instrumento de planeación nacional vigente plantea a través de cinco grandes metas nacionales las políticas que rigen el país: México en Paz; México incluyente; México con educación de calidad; México Próspero; y México con responsabilidad global. Nuevamente, el tema de la seguridad se ubica en la primera mención (aunque en teoría todas las metas tienen la misma prioridad). México en Paz es la meta que "responde a un nivel de inseguridad que atenta contra la tranquilidad de los mexicanos".

Una de las estrategias más importantes de este Plan, para incidir en el mejoramiento de las condiciones de seguridad pública "Aplicar, evaluar y dar seguimiento del Programa Nacional para la Prevención Social de la Violencia y la Delincuencia". No se especifican en este punto acciones sobre espacios públicos o relativas a temas urbanos.

\section{Programa Nacional de Prevención Social de la Violencia y Delincuencia 2014-2018 (PRONAPRED)}

De acuerdo con el Diario Oficial de la Federación publicado el 30 de abril de 2014, el Programa Nacional para la Prevención Social de la Violencia y la Delincuencia (PNPSVD, Ilamado también PRONAPRED) tiene por objeto atender los factores de riesgo y de protección vinculados a los fenómenos que refiere, y parte de que la prevención social es un proceso que demanda acciones de corto, mediano y largo plazos orientadas a lograr, de manera progresiva, cambios socioculturales que permitan la configuración de relaciones libres de violencia y delincuencia.

Desde el año 2013, tres municipios del Estado de México, Toluca, Ecatepec y Nezahualcóyotl, fueron designados para recibir recursos federales aplicables a acciones de prevención social de la violencia y la delincuencia. En el año 2015 se incorporó Metepec. El municipio de Toluca cuenta con una partida presupuestal federal para realizar diversas acciones de prevención en cuatro polígonos específicos seleccionados por su alto nivel de conflictividad urbana. Uno de ellos, Barrios Tradicionales, es el que se presenta como estudio de caso en el presente trabajo.

\section{Plan de Desarrollo Municipal de Toluca, 2016-2018}

Este plan se caracteriza por hacer un gran énfasis en la importancia del espacio público, con nuevos enfoques urbanísticos y una ligera inclinación a plantear el espacio público como factor para la seguridad ciudadana. El plan cuenta con un diagnóstico, con prospectiva para cada tema, creación de escenarios deseables, y definición de variables e indicadores para evaluar las acciones. Resalta en este Plan que el espacio público se convierte en un Eje rector de la política pública: es el eje 3, denominado Mejores calles y espacios públicos. 


\section{DISEÑO METODOLOGICO}

En este apartado se describe la forma en que se abordará el problema de investigación a fin de corroborar la validez de la hipótesis propuesta. Describe la metodología, los métodos, técnicas e instrumentos que permitirán poner la prueba tanto hipótesis como objetivos de investigación y dar respuesta a las preguntas de investigación.

Desde un inicio se ha procurado hacer énfasis en que la investigación de fenómenos relacionados con la inseguridad requiere, dada su complejidad, un abordaje que reconozca la necesidad de "ver el panorama completo" para comprender los fenómenos sociales. Por ello, se construyó un andamiaje teórico que integrara al menos tres planteamientos disciplinarios que ayudan a entender la realidad de los espacios públicos urbanos: el urbanismo, la seguridad ciudadana y el análisis de las políticas públicas.

Esta investigación se abordará con un enfoque mixto, pues se considera que es el diseño que permite buscar y encontrar la convergencia de resultados sobre un mismo fenómeno: por un lado, los resultados en materia de inseguridad (incidencia delictiva) y por otra parte, en temas de percepción (sensación de inseguridad). También se busca complementar los datos y generar propuestas explicativas en tanto el problema planteado: las políticas públicas urbanas y de seguridad se aplican para transformar el espacio público, pero este cambio no parece incidir en mejora en la seguridad, aún cuándo la perspectiva teórica y las experiencias internacionales documentan ejercicios exitosos de ese tipo de intervenciones. El diseño mixto también permitirá descubrir paradojas, contradicciones y nuevas perspectivas y explicar con más argumentos por qué el espacio público intervenido a partir de políticas públicas no contribuye a mejorar la seguridad.

Se ha determinado utilizar un diseño de investigación de triangulación, que permite combinar las fortalezas de las metodologías tanto cuantitativas como cualitativas, y se realiza recolectando la información, procesándola y analizándola de forma simultánea.

En este caso, la recopilación de datos cuantitativos y cualitativos, es concurrente, pasando durante una fase del estudio de investigación. Idealmente, la prioridad sería que esta recopilación de datos fuese igual entre los dos métodos. Este diseño integra por lo general los resultados de los dos métodos en la fase de interpretación. Esta interpretación ya puede tomar nota de la convergencia de los resultados como una manera de fortalecer el conocimiento del estudio y también debe explicar la falta de convergencia que pueda resultar del mismo estudio.

\section{Definición de dimensiones y variables}

Considerando los planteamientos de Jahn Gehl (2014) a partir de la humanización de la ciudad, en la que sostiene que urbanismo aspira a crear ciudades vitales, sostenibles, seguras y sanas, se desprende que una ciudad segura se obtiene al aumentar la cantidad de población que resida y circule dentro del espacio urbano.

Lynch (2008), por su parte, plantea la legibilidad de la ciudad, con el que denomina la facilidad con que pueden reconocerse y organizarse las partes de la ciudad en una pauta coherente. Una ciudad cuyos elementos son identificables fácilmente en una pauta global. Propone: sendas, barrios, nodos, mojones, bordes. Metodología: la entrevista de una pequeña muestra de ciudadanos con respecto a su imagen del medio ambiente; $y$, por otra parte, el examen sistemático de la imagen ambiental evocada en observadores profesionales sobre el terreno.

Para Newman, con su teoría del espacio defendible, plantea la territorialidad y la distinción entre el espacio público y privado, pues la territorialidad genera un sentido de propiedad que aumenta la responsabilidad personal, la vigilancia y un sentimiento protector por parte del residente que puede prevenir el crimen.

Hillier, a partir de la sintaxis espacial, propone la integración: mayor o menor relación de accesibilidad, tanto peatonal como vehicular, de los espacios estudiados a todos los otros espacios del sistema. También el encuentro, que vincula espacio, cuerpos, movimiento y comunicación potencial cara a cara. Medio ambientes más integrados promueven la vigilancia natural.

Jacobs, y el control natural del espacio: gente y movimiento constantes, manzanas no muy grandes que generen numerosas esquinas y cruces de calles; donde los edificios miren hacia la acera para que muchos 
ojos la custodien. Le denomina "ojos en la calle" a la casual, pero constante vigilancia que los caminantes de paso y residentes ejercen desde las ventanas de los edificios a las diversas actividades realizadas en el espacio público.

Los espacios públicos son áreas de suelo donde la gente lleva fuera sus actividades funcionales y rituales que unen a la comunidad, ya sea en las rutinas de la vida diaria o en sus festividades periódicas; o, es el escenario sobre el cual el drama de la vida de la comunidad se desarrolla

De manera más concreta en relación al espacio público, Gehl propone evaluar la usabilidad del espacio, el uso del espacio público contribuye a mejorar las condiciones de seguridad. Las actividades exteriores pueden ser: necesarias, opcionales y sociales. Cuando existe un buen ambiente, las actividades necesarias no cambian, pero las opcionales y sociales se ven incrementadas.

A partir de estos planteamientos teóricos, se definen las variables a evaluar. Y los indicadores se desarrollan a partir del análisis de las propuestas de evaluación revisadas en el capítulo 2 , y reagrupando de forma coherente con las dimensiones planteadas. En los siguientes cuadros se muestra el diseño metodológico planteado al momento para alcanzar los objetivos de la investigación, y el tipo de información que se espera obtener de acuerdo a la técnica y al instrumento planteado.

\section{Cuadro No.}

Definición de variables e indicadores

\begin{tabular}{|c|c|c|}
\hline DIMENSIÓN & Variables & 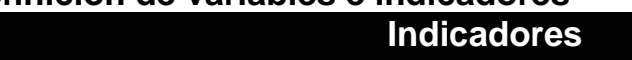 \\
\hline \multirow[t]{4}{*}{$\begin{array}{l}\text { Diseño } \\
\text { urbano }\end{array}$} & Accesibilidad & $\begin{array}{l}\text { Medios de acceso } \\
\text { *Ubicación }\end{array}$ \\
\hline & Mobiliario & $\begin{array}{l}\text { Tipo } \\
\text { * Calidad/Condición }\end{array}$ \\
\hline & Seguridad & $\begin{array}{l}\text { Equipo/Infraestructura } \\
\text { Cercanía } \\
\text { * Iluminación }\end{array}$ \\
\hline & Legibilidad & $\begin{array}{l}\text { Señalización } \\
\text { Sendas, nodos, mojones, bordos } \\
\text { * Comprensión del espacio }\end{array}$ \\
\hline \multirow[t]{6}{*}{$\begin{array}{l}\text { Función } \\
\text { social }\end{array}$} & $\begin{array}{l}\text { Actividades } \\
\text { realizables }\end{array}$ & $\begin{array}{l}\text { Tipo de actividades } \\
* \text { Variedad/Usuario }\end{array}$ \\
\hline & Mobiliario & $\begin{array}{l}\text { Mobiliario usado } \\
{ }^{*} \text { Pertinencia del uso }\end{array}$ \\
\hline & $\begin{array}{l}\text { Diversidad de } \\
\text { usuarios }\end{array}$ & $\begin{array}{l}{ }^{*} \text { Edad } \\
{ }^{*} \text { Sexo }\end{array}$ \\
\hline & Uso del espacio & $\begin{array}{l}\text { Aforo } \\
{ }^{*} \text { Actividades realizadas }\end{array}$ \\
\hline & Oferta cultural & $\begin{array}{l}\text { Número y tipo de actividades culturales } \\
{ }^{*} \text { Aceptación de tales actividades }\end{array}$ \\
\hline & Apropiación & $\begin{array}{l}\text { Vínculo con el espacio } \\
\text { Aprecio por el espacio } \\
\text { * Expectativa del espacio }\end{array}$ \\
\hline
\end{tabular}




\begin{tabular}{|c|c|c|}
\hline \multirow[t]{6}{*}{$\begin{array}{l}\text { Socio- } \\
\text { territorial }\end{array}$} & Vialidades & $\begin{array}{l}\text { *Vialidades primarias } \\
\text { Vialidades secundarias } \\
\text { * Vialidades terciarias }\end{array}$ \\
\hline & Uso de suelo & * Comercial, habitacional, industrial \\
\hline & Presencia policial & *Índice (municipal) \\
\hline & Demografía & $\begin{array}{l}\text { *Total } \\
\text { *Sexo } \\
\text { *Edad }\end{array}$ \\
\hline & Equipamiento & $\begin{array}{l}\text { * Cementerios, médicos, mercados, plazas, templos, } \\
\text { transporte, escuelas, instalaciones deportivas. }\end{array}$ \\
\hline & Servicios & *Viviendas con servicios básicos \\
\hline
\end{tabular}

Las técnicas a aplicar para la recolección de la información pertinente para la tesis, fueron el análisis georreferenciado, la observación sistémica urbana (con fundamento en CPTED), el análisis del diseño urbano y el análisis de contenido (grupos de enfoque y entrevistas). Asimismo, se recurrió a la técnica de la Observación Sistémica Urbana, que permite apreciar informaciones sobre la ciudad en términos comparativos respecto de algún parámetro que permita una conclusión racional acerca de la realidad a valorar.

\section{Caracterización del caso de estudio: Toluca}

La investigación que da origen a este artículo problemática planteada en el municipio de Toluca, Estado de México, considerando los espacios públicos de los polígonos que son objeto de la política pública federal de prevención social, es decir, la colonia El Seminario, San Lorenzo Tepaltitlán, Barrios Tradicionales y San Sebastián. La ubicación territorial en la Zona Metropolitana del Valle de Toluca es la siguiente:

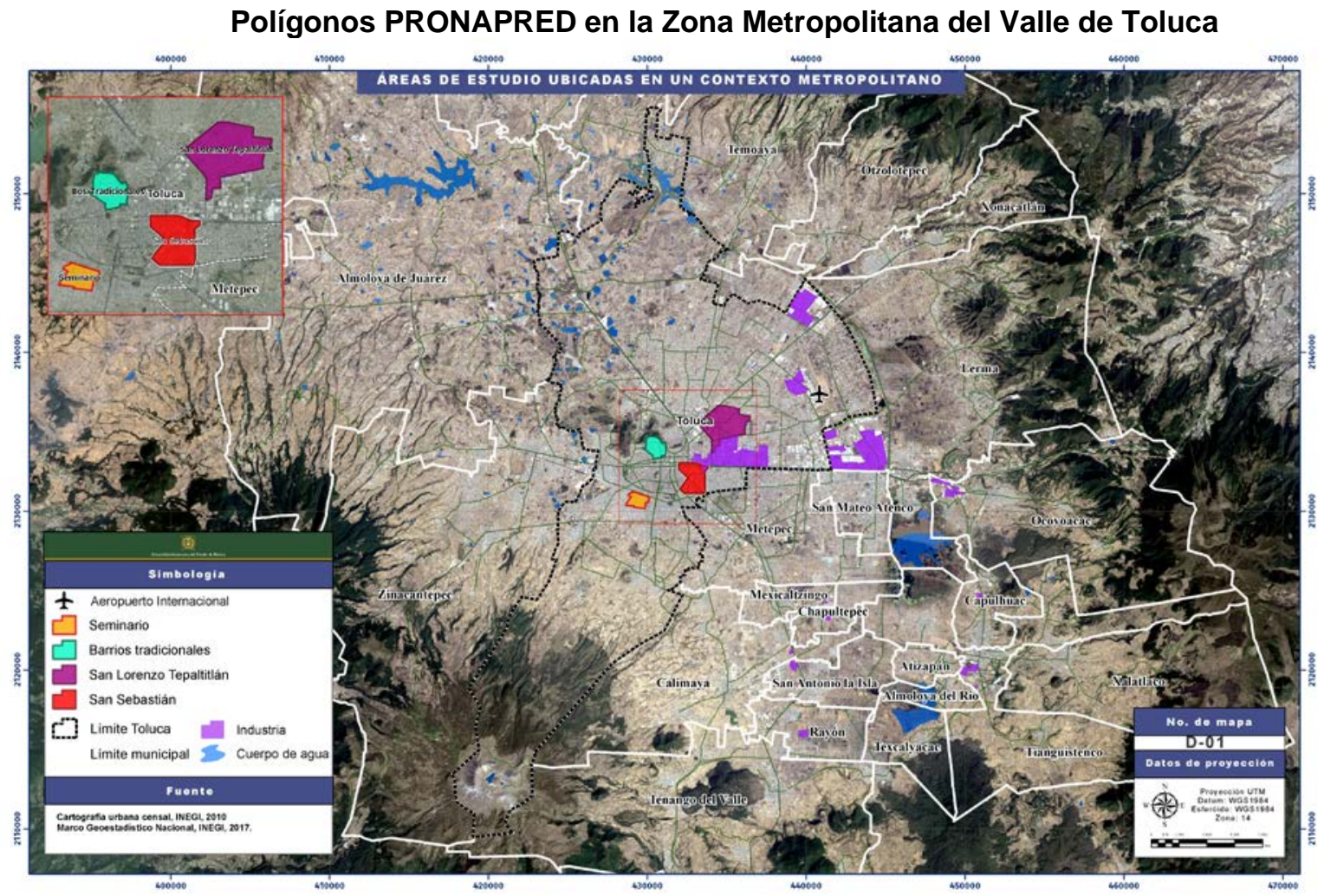

Fuente: Elaboración propia con datos del PRONAPRED, 2016. 
El municipio de Toluca recibe dichos recursos para los polígonos específicos que han sido seleccionados por su nivel de conflictividad urbana. En primera instancia estos polígonos, que han sido definidos en función de los límites de las colonias, son los primeros espacios a ser considerados como parte del estudio de caso.

Sin embargo, se ha considerado ampliar el ámbito de estudio, de forma que se incluyan más espacios públicos en el municipio, lo que permitirá también un análisis comparativo. Esta propuesta está en función de los hallazgos sobre la concurrencia de políticas públicas de nivel estatal y municipal en diferentes espacios. A fin de definir cuáles serían los espacios a estudiar, se han planteado los criterios siguientes:

- Ubicación territorial en zona urbana de Toluca

- Haber sido objeto de intervención (remodelación, recuperación, creación) a partir de recursos federales, estatales o municipales

- Que dicha intervención tenga como fin mejorar las condiciones del entorno o se encuentre relacionada con las acciones de PRONAPRED

Se ha definido que sean intervenciones a evaluar aquellas que cumplan la característica d ser espacios públicos abiertos que han sido intervenidos con políticas públicos federales, estatales o municipales, con el fin de obtener mejores condiciones de seguridad, en el periodo 2006 a 2016. Este periodo abarca el inicio de las políticas públicas que, desde el nivel federal retoman el tema de los espacios públicos urbanos para fines de seguridad y de mejorar las condiciones de seguridad a partir de la intervención en los espacios públicos. A partir de esto, se define que para el polígono Barrios Tradicionales, se estudie el MacroMural realizado en el año 2016.

\section{POLIGONO BARRIOS TRADICIONALES}

\section{Polígono 1. Barrios Tradicionales (El Cóporo y Santa Bárbara)}

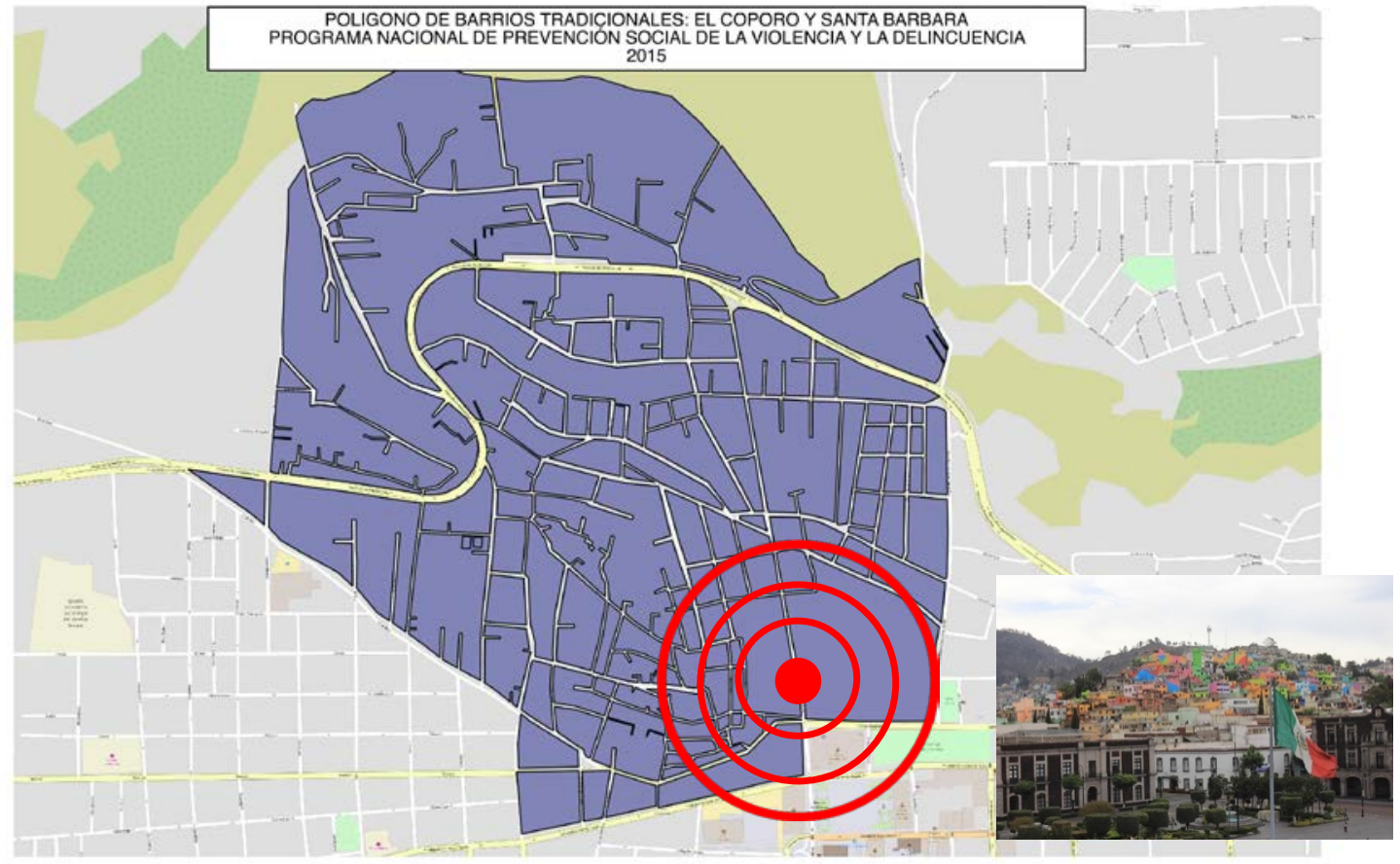

\section{ANALISIS DEL POLÍGONO BARRIOS TRADICIONALES}

EI PRONAPRED considera para su evaluación, la indagación sobre el tema de Espacios públicos para la convivencia insuficientes y deteriorados. Requiere que se diagnostique a través de diagnósticos participativos y en campo, a través de las metodologías denominadas marchas exploratorias, y conforme las reglas de operación y normas específicas emitidas para la presentación de la evaluación anual. En el tema, se exploran dos aspectos en cada polígono: Infraestructura cultural y recreativa para la ciudadanía; e, infraestructura y características del espacio urbano. 
De acuerdo con el diagnóstico participativo y en campo, elaborado por el proyecto Pro-Región/UNAM, para el año 2016 en los polígonos intervenidos por el PRONAPRED, los hallazgos más significativos en términos del espacio público, son: en cuanto a la Infraestructura cultural y recreativa para la ciudadanía, en Barrios tradicionales en el $7.1 \%$ de las calles existe algún parque; en el $21.4 \%$ alguna iglesia y en el $7.1 \%$, algún tipo de explanada; mientras que en lo referente a la infraestructura y características del espacio urbano, en Barrios Tradicionales, el $14.3 \%$ de las calles cuenta con teléfonos públicos y el $100 \%$, con postes de luz. En el $92.8 \%$ no hay botes para la basura; en el $85.7 \%$, letreros y, en el $28.5 \%$, banquetas; el $21.4 \%$ de las calles se encuentran sucias; el $67.1 \%$, descuidadas, mientras que el $35.7 \%$ se observan solas; el $42.8 \%$ de los cables de alumbrado público están colgados y el $50 \%$ de los postes de luz se hallan en mal estado.

La metodología de evaluación del PRONAPRED también solicita indagar sobre la incidencia delictiva en las zonas. Sobre este tema, y siguiendo siempre los resultados del estudio de Pro-Region/UNAM, en Barrios Tradicionales el $10.3 \%$ de los entrevistados menciona que es muy frecuente que haya gente disparando algún tipo de arma de fuego; $10.5 \%$ se ve asaltando casas, vehículos y negocios y el $6.1 \%$ amenazas y extorsiones.

Los delitos mencionados como recurrentes en los cuatro polígonos, son: robo a casa habitación; robo de autos; robo a mano armada y asaltos a transeúntes; robo a establecimientos. Un dato fundamental es que hay un nivel de victimización recurrente hacia las mujeres, en especial las más jóvenes, por acoso callejero y en el transporte público. Este problema fue mencionado en los cuatro polígonos. Destacan las respuestas coincidentes en los cuatro polígonos, al cuestionarse sobre las posibles causas de la violencia y la delincuencia en sus colonias, siendo estas respuestas relacionadas, entre otras, con la falta de espacios públicos y recreativos, su deterioro y mal estado. Así también se menciona la inseguridad en los propios espacios públicos, mencionados en Barrios Tradicionales y Seminario Conciliar.

El polígono 1, Barrios Tradicionales, se compone con el 51\% de mujeres y el $49 \%$ de hombres, en el cual habitan más jóvenes con un $24.5 \%$, siendo que el $13 \%$ de los jóvenes de 15 a 24 años está casado o unido, el $23 \%$ de habitantes son niños, y con menor densidad los adultos mayores con un $7.3 \%$.

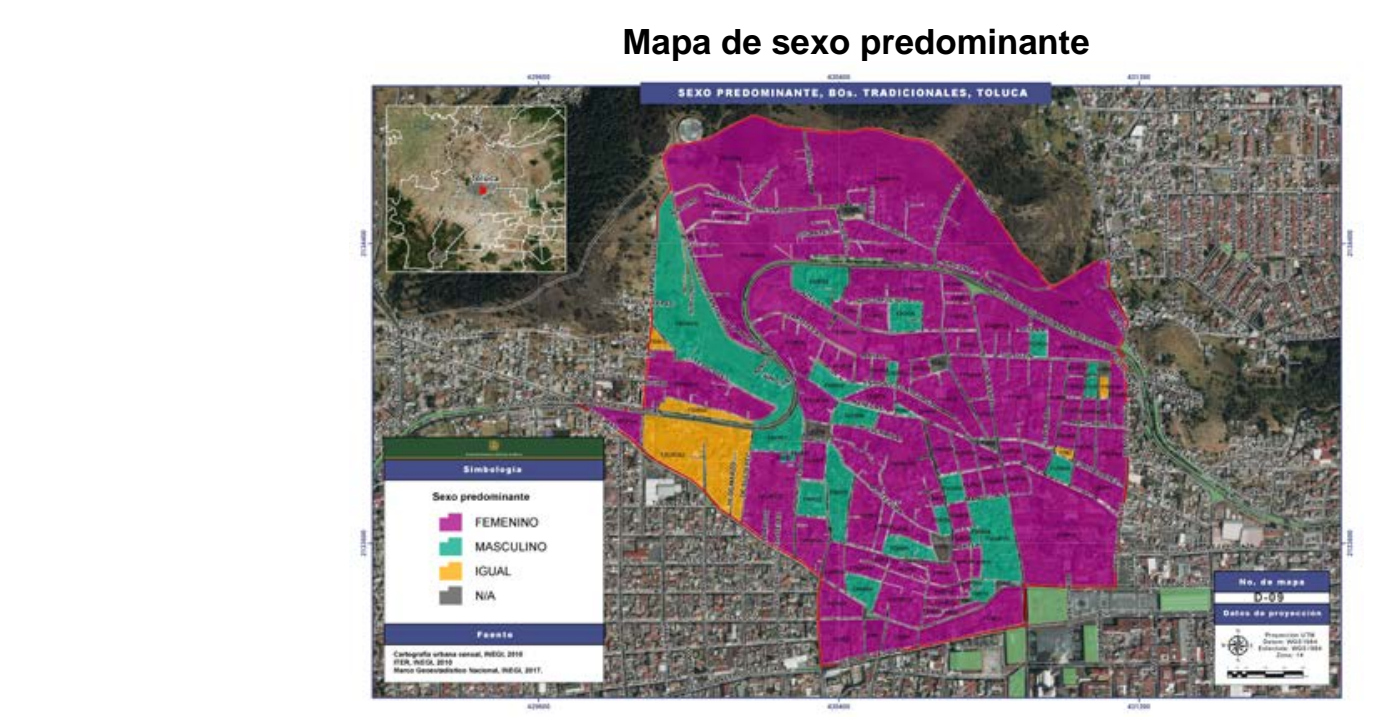

Fuente: elaboración propia con datos del INEGI

En cuanto a educación el 2\% de la población de 8 a 14 años no sabe leer y escribir, y con el mismo porcentaje población de 15 años más es analfabeta. El $67.4 \%$ de los habitantes del polígono son no económicamente activas, mientras que el $24 \%$ del total de los habitantes no son derechohabientes a servicios de salud y el $72 \%$ de los hogares tienen jefatura masculina.

El grado de marginación del polígono es medio, ya que el $2 \%$ del total de las viviendas habitadas tienen piso de tierra, el $3 \%$ tienen un solo cuarto, el $1 \%$ no disponen de agua entubada y el $51 \%$ no cuentan con computadora ni internet. Se rescatan algunos datos relevantes para la investigación en curso, en relación a los factores de riesgo detectados por el PRONAPRED.

Resalta que se observa consumo generalizado de alcohol entre la población. El $66.6 \%$ de la población (encuestada) ha consumido algún tipo de bebidas alcohólicas; el $62.2 \%$ ha bebido hasta embriagarse. El 
$50.3 \%$ ha fumado cigarros, mientras que el $16.9 \%$ ha consumido mota; el $8.1 \%$ ha inhalado mona; el $6.8 \%$ ha consumido algún tipo de alucinógeno y el $4.9 \%$ éxtasis. El $26.6 \%$ de ellos han obtenido las sustancias consumidas con amigos; el $23.9 \%$ las ha conseguido en la escuela y el $23.4 \%$ en la colonia.

Destaca la baja deserción escolar, aunque de acuerdo a las encuestas de este estudio, el $81.2 \%$ de los jóvenes encuestados considera que en la escuela no enseñan nada nuevo; el 10.3\% considera que de todos modos gana lo mismo y el $8.5 \%$ piensa que lo que enseñan no sirve para nada.

Sin embargo, en Barrios Tradicionales destaca la condición socioeconómica de sus residentes. De acuerdo con el estudio, la Población no económicamente activa alcanza un 34\%. Y la población femenina no económicamente activa, alcanza un $71 \%$, lo cual indica un alto nivel de vulnerabilidad para las mujeres.

Asimismo, destaca que el elemento cultural-religioso como cohesionador de la comunidad, pues el $31.4 \%$ de la población se reúnen para eventos religiosos, mientras que sólo el $21.4 \%$ para soluciona problemas de servicios públicos y el 21.1\% para solicitar servicios a la delegación o municipio. El porcentaje de participación baja cuando se trata de organizar seguridad en la colonia, pues es de sólo 15.7\% de los encuestados; sin embargo, destaca que el $67.2 \%$ confía en la gente de su colonia.

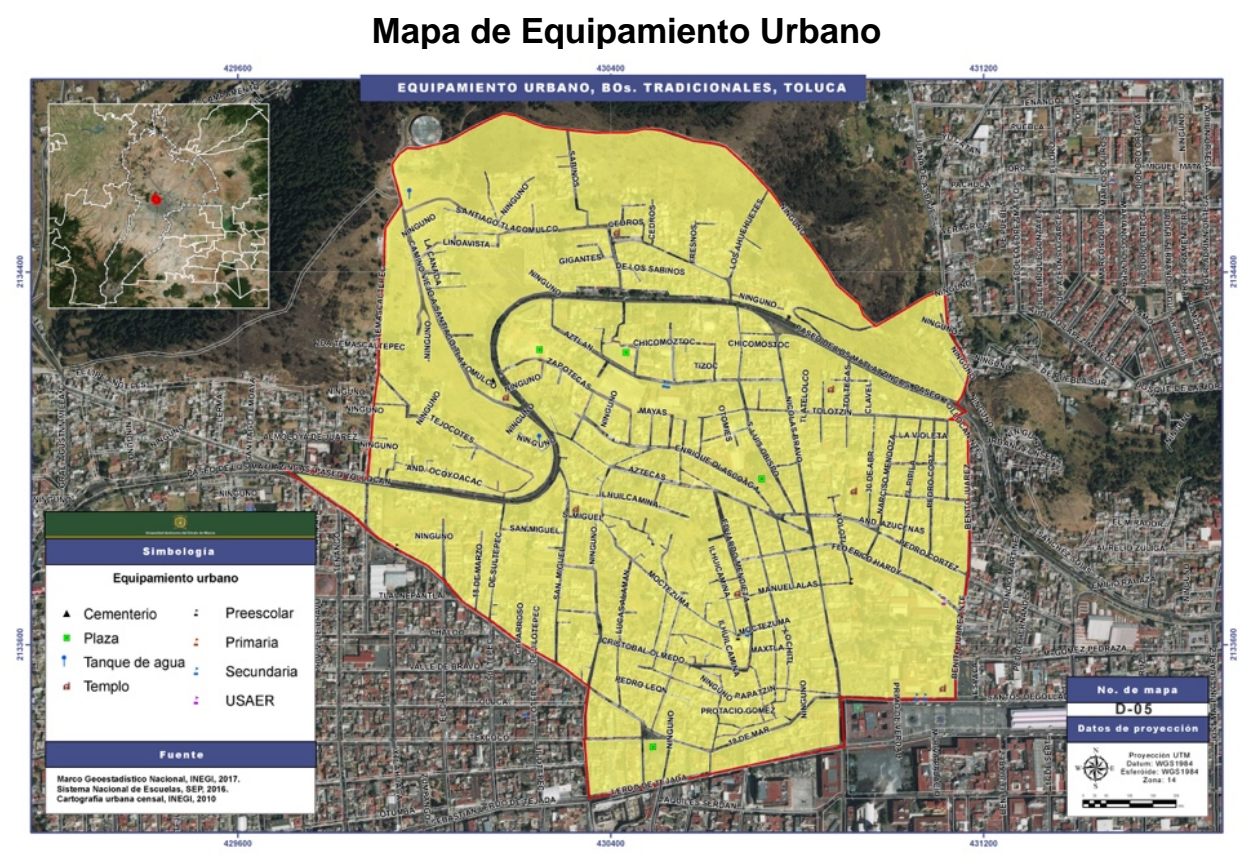

Sobre las características de la vivienda, ingreso y accesos a servicios, el diagnóstico plantea que que no hay suficiente espacio en su vivienda; el $94.4 \%$ no hay suministro de agua y el $91.7 \%$ refiere que el servicio de energía eléctrica no es continuo. El nivel de marginación es medio-bajo, pues sólo el $2 \%$ de las viviendas con piso de tierra; sólo hay un $3 \%$ de viviendas con un solo cuarto; sólo un $1 \%$ de viviendas sin disponibilidad de agua entubada; pero, hayun $51 \%$ de viviendas sin disponibilidad de computadora e internet. 


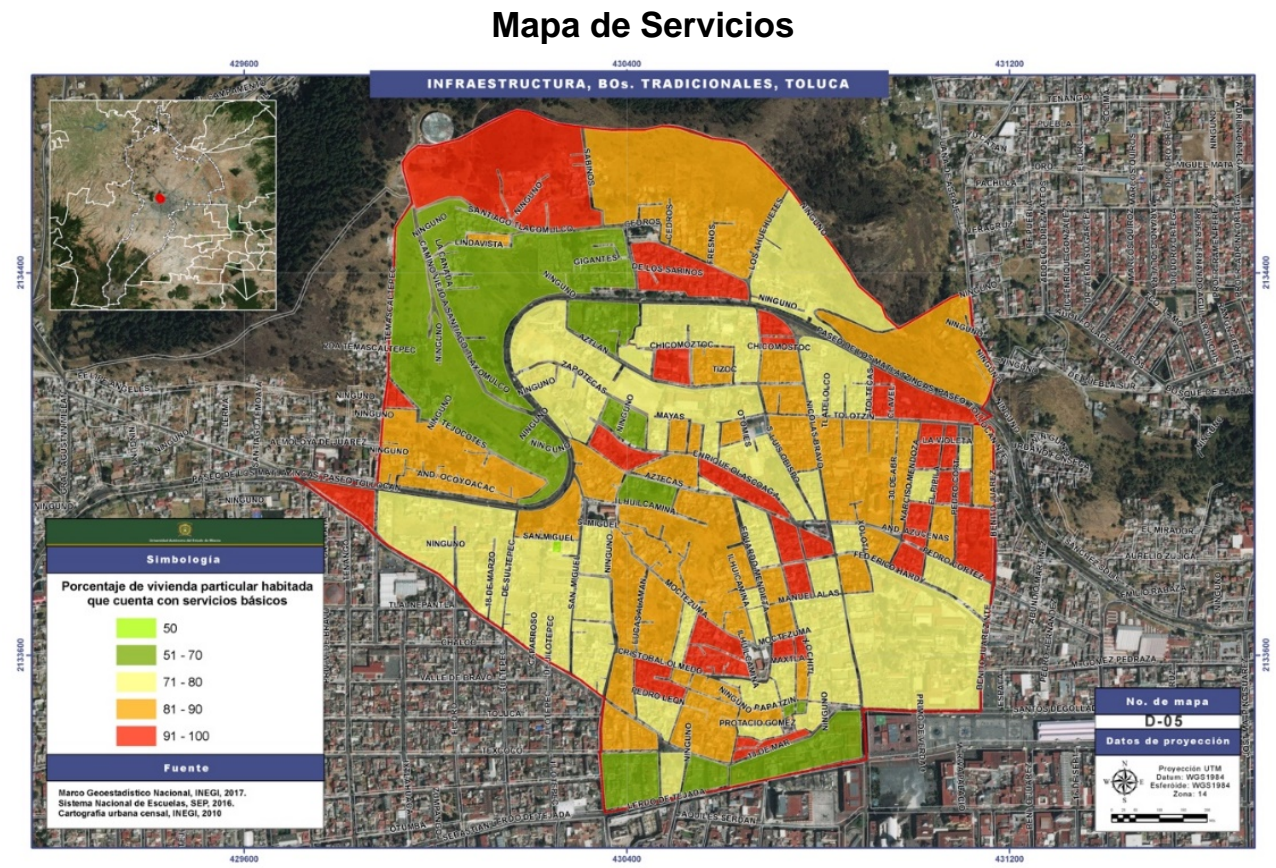

Fuente: elaboración propia con datos del INEGI

Se ha determinado, para fines de esta investigación, el planteamiento de otros datos relevantes sobre Barrios Tradicionales, expresados en el análisis georreferencial. Estos deben ayudar a comprender mejor la territorialidad del espacio.

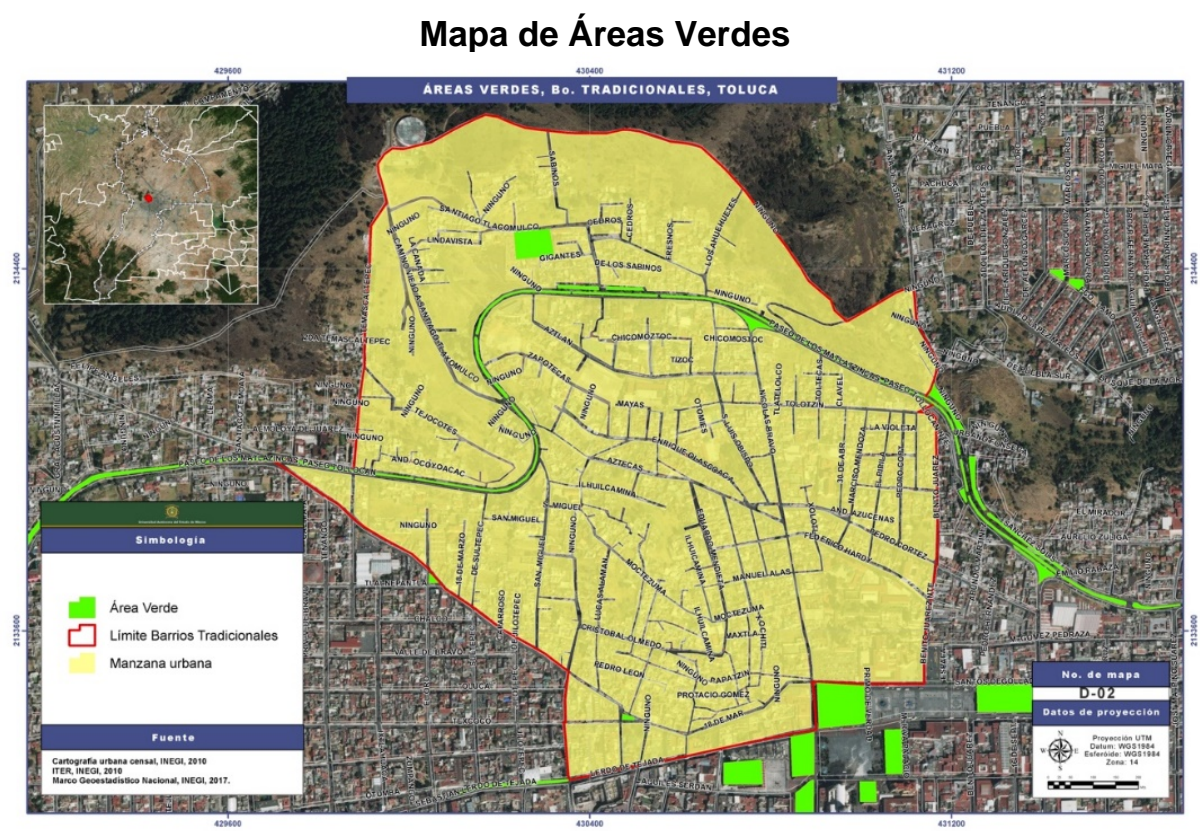

Fuente: elaboración propia con datos del INEGI 


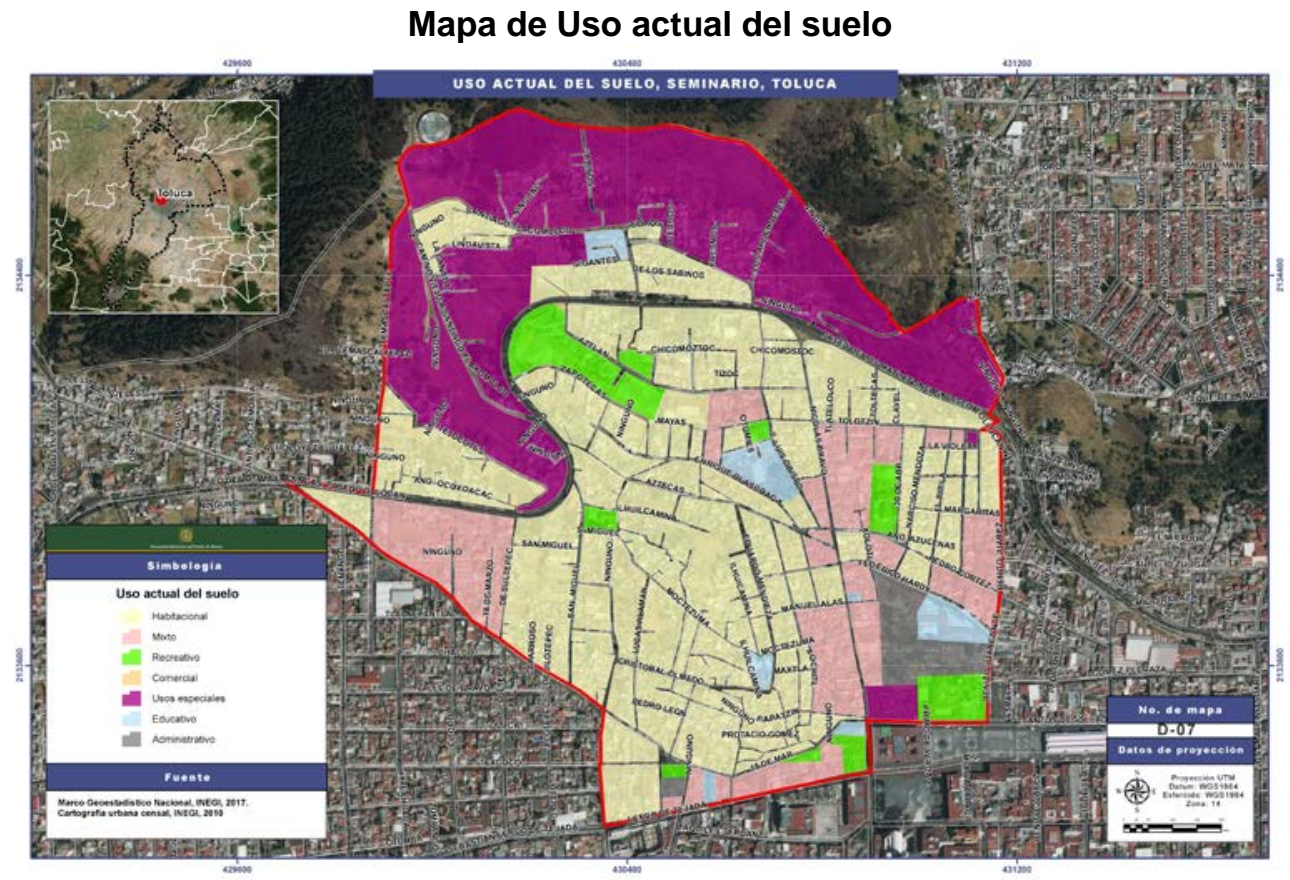

Fuente: elaboración propia con datos del INEGI

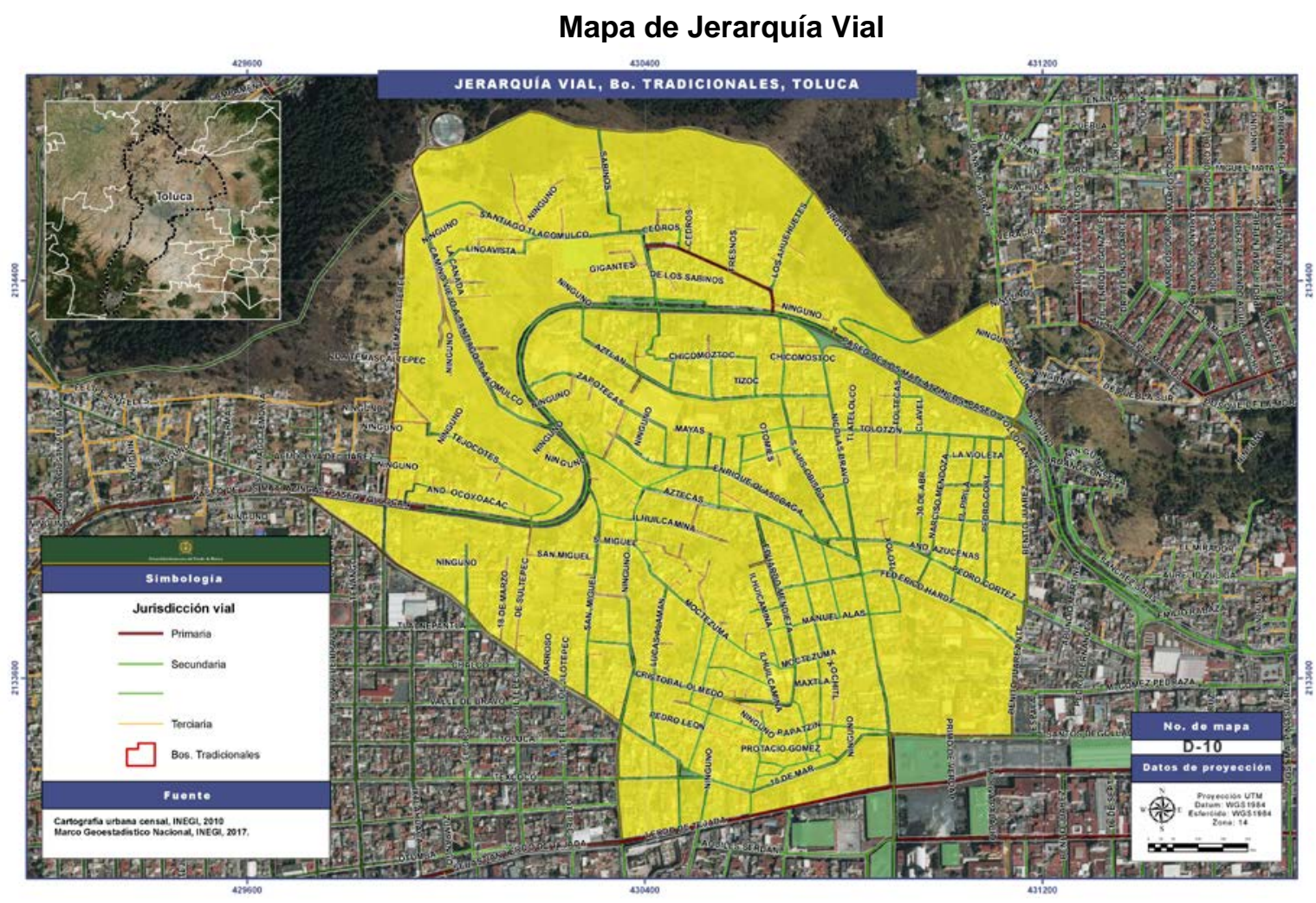

Fuente: elaboración propia con datos del INEGI

En el estudio Pro-Región, se les preguntó a los pobladores de los polígonos se les pregunto si existen ciertas infraestructuras, las cuales se muestran en la siguiente tabla: 
INFRAESTRUCTURA CULTURAL Y RECREATIVA PARA LA CIUDADANÍA

\begin{tabular}{|c|c|c|}
\hline Pregunta: ¿Existen las siguientes infraestructuras en tu colonia o barrio? & Sí & No \\
\hline $\begin{array}{c}\text { Hay centros de salud cercanos (hospitales, clínicas o centros de atención a } \\
\text { adicciones) }\end{array}$ & $5.5 \%$ & $94.5 \%$ \\
\hline Hay lugares de esparcimiento cercanos (parques o jardines) & $4.4 \%$ & $95.6 \%$ \\
\hline Hay plazas públicas o centros comerciales cercanos & $6.1 \%$ & $93.9 \%$ \\
\hline $\begin{array}{l}\text { Hay mercados o lugares cercanos para adquirir artículos de primera necesidad } \\
\text { (alimentos, medicamentos, aseo personal, limpieza, etc.) }\end{array}$ & $3.6 \%$ & $96.4 \%$ \\
\hline Hay escuelas o bibliotecas públicas cercanas & $10.1 \%$ & $89.9 \%$ \\
\hline $\begin{array}{l}\text { Hay cines, teatros o centros culturales cercanos (escenarios públicos para } \\
\text { grupos musicales, bailes, festivales, etc.) }\end{array}$ & $2.4 \%$ & $97.6 \%$ \\
\hline $\begin{array}{l}\text { Hay lugares para acceder a internet cercanos (cibercafés, bibliotecas públicas, } \\
\text { etc.) }\end{array}$ & $3.5 \%$ & $96.5 \%$ \\
\hline
\end{tabular}

Fuente: Pro-Región UNAM 2017

Como se puede observar en la tabla, los habitantes del polígono que existen muy pocas espacios públicos para la convivencia de la población. Lo que más se tiene son escuelas o bibliotecas públicas (10.1\%), el 6.1\% menciono tener plazas o centros comerciales y el 5.5\% dijo tener un centro de salud cercano a casa.

Finalmente, se retoma uno de los mapas integrales del diagnóstico de Barrios Tradicionales, que resume varias de las vulnerabilidades más importantes y las concentra en una zona específica:

\section{Mapa de Vulnerabilidad General de Barrios Tradicionales}
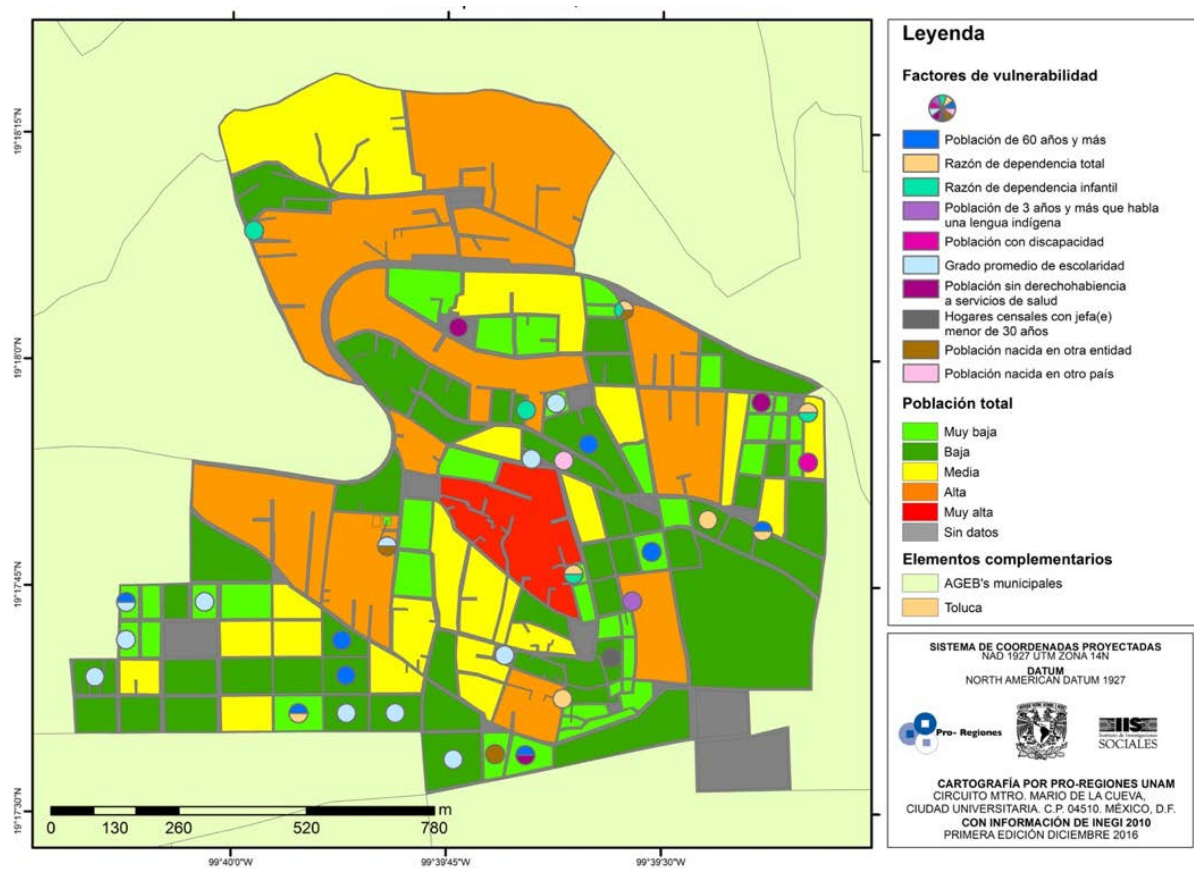

Fuente: Pro-Región/UNAM, 2017 


\section{Grupo de enfoque}

Se realizó el 10 de noviembre de 2017, en el centro comunitario del Barrio de Santa Bárbara, adjunto a la iglesia del mismo nombre. Se convocó a 7 participantes, en su mayoría mujeres, de diferentes edades. Participan en varias de las actividades vinculadas al PRONAPRED en Barrios Tradicionales.

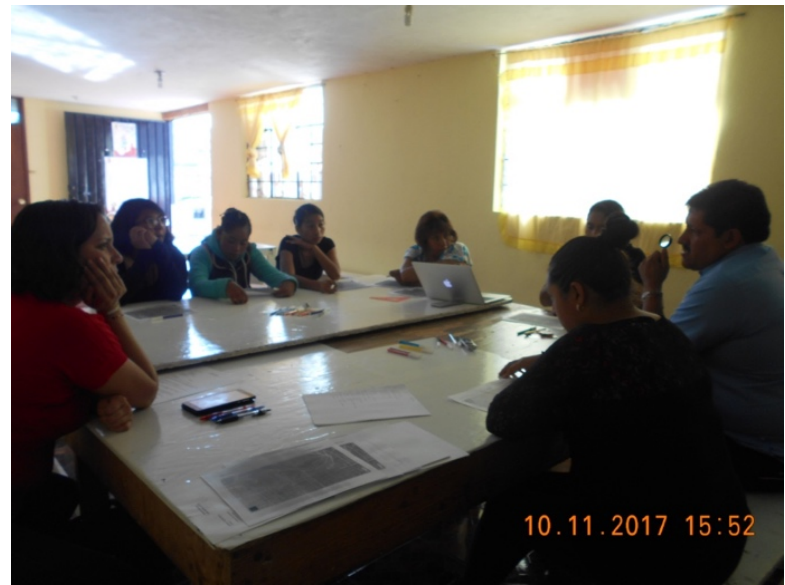

Se realizaron los tres ejercicios propuestos: mapa de ubicación de la colonia o barrio; mapa de lugares emblemáticos o importantes del barrio; y recorridos cotidianos en la zona. Ello, para cubrir los indicadores y variables que se pretenden indagar.

\section{PRODUCTOS}
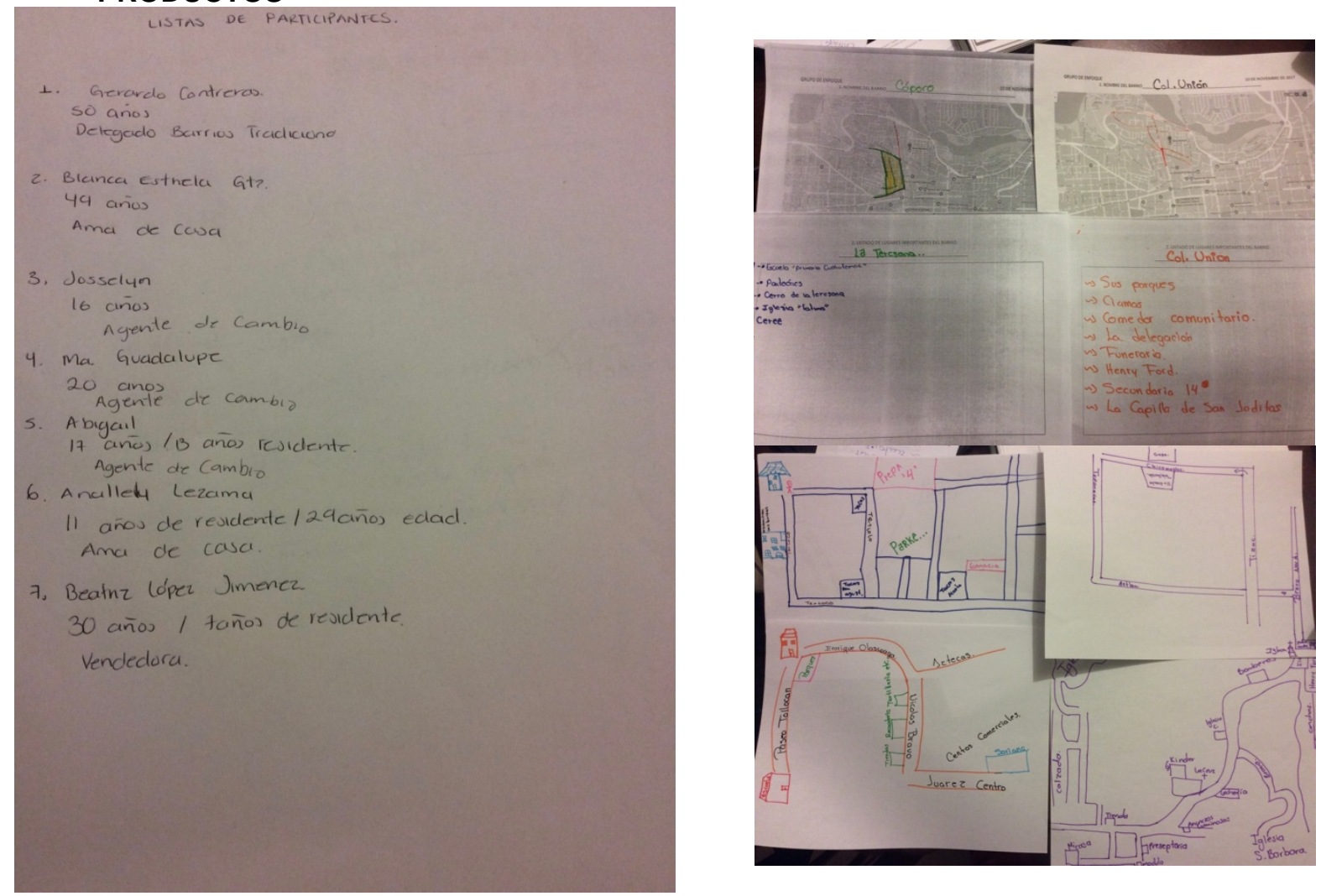

\section{Hallazgos:}

- Algunos de los aspectos más sobresalientes del ejercicio, fueron:

- Los participantes expresaron conocimiento sobre sus colonias

- Les resultó complicado, sin embargo, ubicar en el mapa los límites territoriales de la misma 
- Expresaron conocimiento sobre los lugares más representativos del barrio

- Expresaron conocimiento sobre los principales problemas de la colonia

- Ellos, en particular, no expresaron sentirse inseguros. Sin embargo, reconocen que se cometen delitos en la zona, y que se debe tener cuidado.

- Sobre los espacios emblemáticos, a pregunta expresa sobre el Mural Monumental, manifestaron indiferencia

- Expresaron, sin embargo, entusiasmo por lugares históricos que podrían ser rescatados en lugar de "hacer un mural".

- Se refirieron a un espacio deportivo, canchas; que fueron rehabilitadas y reacondicionadas en la administración anterior, y que volvieron a ser vandalizadas y deterioradas y en la actualidad no se usan, debido a que "los muchachos las usan para drogarse".

- También mencionaron que esas canchan habían sido acondicionadas adecuadamente, y que padres y madres iban ahí con sus hijos. Pero se deterioraron, rompieron el alumbrado público y ya no son usadas.

- Manifiestan que no hay actividades culturales o recreativas en la zona, ni en las colonias específicamente.

\subsubsection{Recorridos}
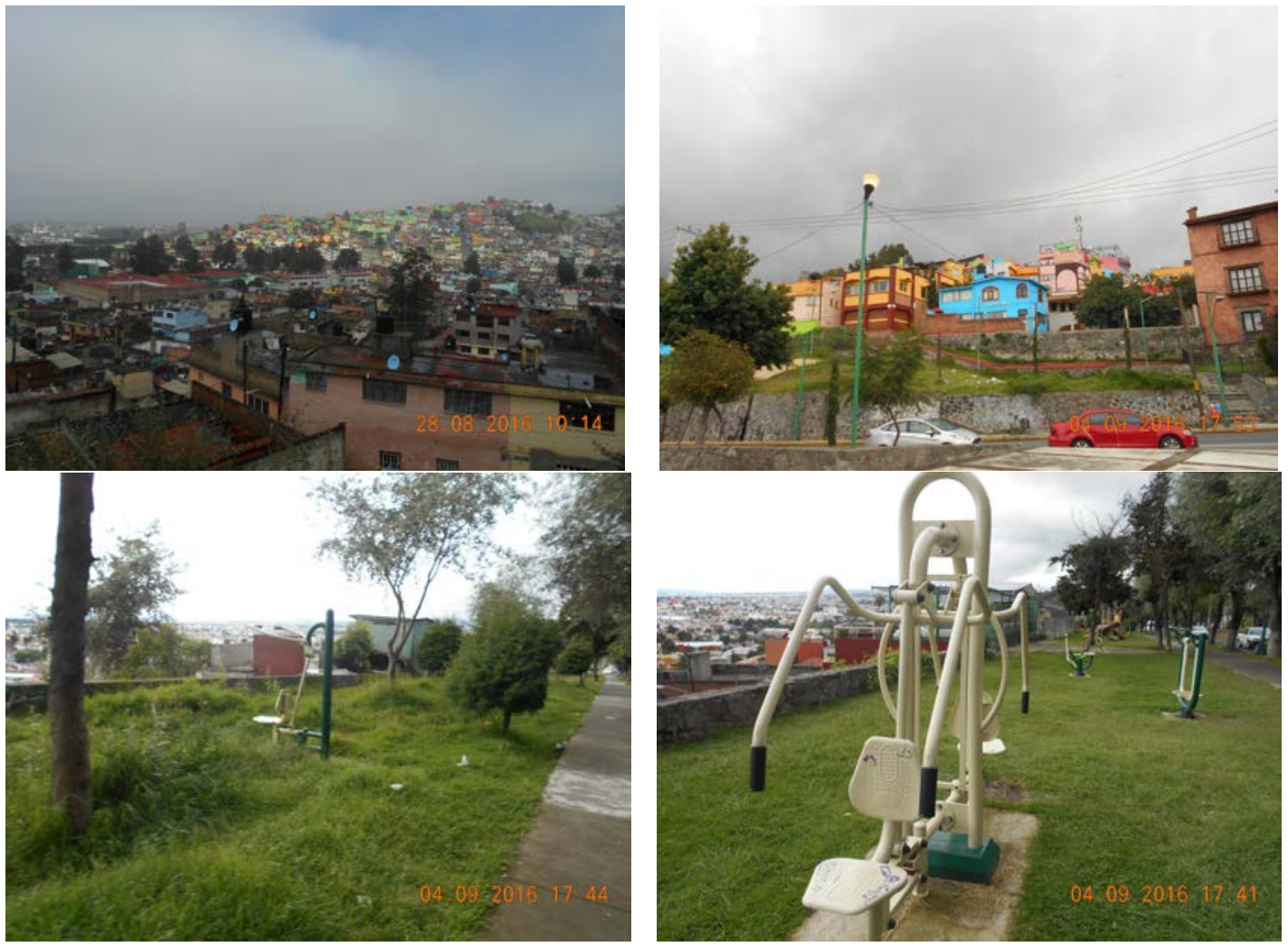

\section{Conclusiones}

El espacio público es uno de los elementos indispensables de la conformación urbana moderna. Es la contraparte del espacio privado, y representa la parte de la ciudad que pertenece a todos y al mismo tiempo, a nadie. Su uso es abierto y no implica restricciones. Es lo que implica lo público. Sin embargo, en la ciudad del siglo XXI el debate por lo que es el espacio público, lo que debe ser, y las funciones y efectos que genera en las dinámicas urbanas, está vigente, en particular cuando lo que sucede en el espacio público es detonante de seguridad o de violencia social. A partir del planteamiento de las condiciones que el espacio público cumple en el entramado urbano, se reconsidera al mismo también en tanto los efectos que puede estar planteando en términos de seguridad. 
El espacio público debe ser un territorio ocupado por personas; los modelos de prevención que se apliquen deben considerar la situación del entorno (prevención situacional), pero principalmente deben considerar las condiciones sociales de las personas que ocupan ese espacio (prevención social). No se puede sólo mejorar el espacio, sino que hay que favorecer procesos sociales o bien las capacidades a nivel personal y colectivo de las comunidades orientados a la prevención de las violencias y la delincuencia.

Las intervenciones en el espacio público se han convertido en emblemas de políticas públicas de prevención y seguridad en acción. En el tema de la política pública se observa una confluencia de la política pública de seguridad y la política pública urbana, en tanto una buena política urbana puede ser de hecho una parte importante de la política pública de seguridad; mientras que una política de seguridad ciudadana incluye, necesariamente, elementos de política pública urbana. Así lo han demostrado experiencias en diferentes partes del mundo, en las que se ha demostrado que a partir de intervenciones urbanas se transforma el panorama de seguridad en que viven las personas, convirtiéndose en referentes y ejemplo de cómo planteamientos teóricos multidisciplinarios influyan en el diseño de políticas públicas y se logre una gran incidencia en la vida social. Al día de hoy, experiencias integrales son consideradas modelos de actuación para que, a través de la transformación del espacio público, se reconstruya o recupere la sensación de seguridad en el espacio público.

A partir de la revisión de políticas y planes federales, estatales y municipales, en relación al espacio público y la seguridad, es posible empezar a concluir, entre otras cosas, que la importancia de los espacios públicos en el ámbito de la planeación va creciendo de forma cronológica, pues los planes más avanzados retoman este elemento urbano como referente de la acción pública. La visión, que podría decirse es propiamente funcionalista, de la ciudad, se percibe va dejando paso a una visión más comprehensiva de la ciudad y sus fenómenos, tratando de incorporar una visión cada vez más de escala humana, así como de reconocimiento de derechos. Esto puede deberse, al menos, a dos aspectos: la propia dinámica urbana del estado de México, y la creación de otros instrumentos de planeación, a nivel local y federal, que ya introducen perspectivas más integrales para la planeación urbana, al menos de forma enunciativa.

El nivel municipal es el que más ha retomado la acción en el espacio público Para Toluca, se ha convertido en un eje de trabajo, a partir del programa 2013, y cada vez con mayores miras a vincularse con los objetivos de tipo social, especialmente convivencia y fortalecimiento del tejido social. Esta línea se mantiene al plan de desarrollo vigente.

Para el caso de las condiciones del espacio público en los polígonos distan mucho de ser la más deseable. La política pública concentra acciones en lugares específicos, en lugar de crear corredores seguros, a pesar de la información. Los delitos recurrentes son delitos del fuero común, que no son necesariamente los más impactantes, pero si los que laceran de forma cotidiana a las personas. Estos delitos, en su mayor parte, se cometen en el espacio público y es más frecuente y se es más vulnerable en este tipo de espacios. Los diagnósticos corroboran la sensación de inseguridad y la prevalencia de delitos.

Especialmente relevante es el dato de la victimización por género, en tanto la vulnerabilidad de las mujeres, niñas y jóvenes se incrementa, así como el temor y el miedo a desarrollar actividades, incluso las cotidianas, en los entornos públicos. Esto pone énfasis en que los espacios públicos no están cumpliendo la función de generar entornos seguros con perspectiva de género.

Destaca que en Barrios Tradicionales, el diagnóstico dirigido al PRONAPRED no retoma prácticamente ningún indicador cultural. Sin embargo, esta zona retoma mucho de su orgullo histórico, incluso urbano por su arquitectura y edificios históricos, mismo que está vinculado con un sentido de identidad y pertenencia, incluso orgullo territorial. Sin embargo, los diagnósticos no alcanzan a capturar dicha característica. En barrios de este tipo, destaca que se expresa un interés en participar en acciones comunitarias, cuando se trata de temas religiosos o vinculados con la iglesia. Ello, represente un punto de cohesión comunitaria, a pesar de la conflictividad social.

Las políticas federales con enfoque de seguridad han reconocido la importancia del nivel local para la implementación de las propias acciones, incluso para la decisión de las necesidades locales sobre inseguridad que son prioritarias. En particular el PRONAPRED estableció un conjunto de "candados" que permitieran un nivel de decisión al municipio que recibiera recursos de este fondo, pero no tal que pudiera "salirse" de la acción dirigida puntualmente a prevención. De esta forma, se buscó garantizar que los municipios realmente aplicaran los recursos en los verdaderos problemas de prevención, y con ello, evitar desviaciones tales como 
uso político de los recursos, beneficiar a poblaciones que no se encontraban en realidad en riesgo, mal uso de los recursos en acciones no prioritarias, entre otras.

El espacio público intervenido es una expresión de una política pública de seguridad que hace énfasis en prevención primaria y situacional: es decir, es para todos y que busca desincentivar las oportunidades de cometer delitos, pero también de propiciar cierto tipo de relaciones sociales que se convierten en factores protectores. 


\section{REFERENCIAS}

Ayuntamiento de Barcelona (2014) Propuesta orientativa de Superislas. Plan de Movilidad Urbana de Barcelona 2013-2018 BCNecología, en http://ajuntament.barcelona.cat/superilles/es/

Aguilar, L. F. (2009). Marco para el análisis de las políticas públicas. En Mariñez, F. y Garza, V. (2009) Política pública y democracia en América Latina: del análisis a la implementación, pp. 11-32, México, D. F.: Porrúa.

Aguilar, Luis F. (2009) Marco para el análisis de las políticas públicas. En Mariñez, Freddy y Garza, Vidal (2009) Política pública y democracia en América Latina: del análisis a la implementación. Porrúa, México, D. F.

Antes y después en la superisla, en http://ajuntament.barcelona.cat/superilles/es/presentacio.

Arellano, A. (2009) Estado de inseguridad pública en México: los supuestos de la acción estatal. Disponible en: http://www.publicaciones.cucsh.udg.mx/pperiod/estsoc/pdf/estsoc 4/Seccionarticulos3.pdf

Arellano, A., (2004). Estado de inseguridad pública en México: los supuestos de la acción estatal. Recuperado de: http://www.publicaciones.cucsh.udg.mx/pperiod/estsoc/pdf/estsoc 4/Seccionarticulos3.pdf

Borja, J. (1998) Ciudadanía y espacio público. Publicado en VVAA, Ciutat real, ciutat ideal. Significat i funció a l'espai urbà modern, "Urbanitats" núm. 7, Centro de Cultura Contemporánea de Barcelona, Barcelona.

Borja, J., Muxi, Z. (2000) El espacio público, ciudad y ciudadanía. Barcelona.

Brand, P. (2010) Urbanismo social o seguridad democrática en las ciudades,

Cabrera, A. Castillo, M. y Franceschi, P. (2010) Cuaderno de desarrollo humano: La seguridad ciudadana, una tarea compartida. Programa de las Naciones Unidas para el Desarrollo Humano.

Capel, H., (2002). La morfología de las ciudades. Barcelona: Ediciones del Serbal.

Carr, S. (1992) Espacio Público, Cambridge.

Carrión, F. (2001). Espacio público: punto de partida para la alteridad. Facultad Latinoamericana de Ciencias Sociales, FLACSO Ecuador. [Disponible en: http://ebookbrowse.com/1228415744-espacio-publico-punto-de-partida-para-la-alteridad-doc-d45992619].

Carrión, F. (2002). Violencia urbana: un asunto de ciudad. Revista Eure Vol. 34, No. 103, Santiago, Diciembre. [Disponible en: http://www.scielo.cl/scielo.php?pid=S0250-71612008000300006\&script=sci_arttext

Carrión, F. (2008). Violencia urbana, un asunto de ciudad. EURE, vol. XXXIV, núm. 103, diciembre, 2008, pp. 111-130. Santiago de Chile: Pontificia Universidad Católica de Chile.

Cortés, E. (2013) La problemática del espacio público, en Blog Composición Urbana, la buena forma de hacer ciudad. Posteado en 09/12/2013, disponible en http://composicionurbana.blogspot.mx/2013/12/laproblematica-del-espacio-publico.html

Choay, F. (1983) El urbanismo: utopías y realidades. Lumen, Barcelona.

Choque Jarro, J. (2010) ¿Qué es una intervención urbana?, Presentación de diapositivas, consultado el 26/05/15, en http://es.slideshare.net/i1mys/intervenciones-urbanas-concepto

Dammert, L y Paulsen. (2005) La construcción de la ciudadanía como estrategia para el fomento de la convivencia y la seguridad. Seminario permanente sobre violencia. El Salvador.

Dammert, L. (2003). Participación Comunitaria en Prevención del Delito en América Latina, en ¿De qué participación hablamos? Centro de Estudios del Desarrollo, Santiago (2003). www.policiaysociedad.org

Dammert, L. y Lunecke, A. (2004) La prevención del delito en Chile: Una visión desde la comunidad. CESC. Santiago: Chile.

Di Siena, D. (2009) Espacios sensibles, Universidad Politécnica de Madrid.

DiSienna, D. (2013) "Espacio público/Espacio jurídico donde ejercer la ciudadanía”, en Blog Urbano-Humano. Posteado en 10/09/2013, disponible en http://urbanohumano.org//blog/2013/09/10/espacio-publico-espaciojuridico-y-politico-donde-ejercer-la-ciudadania/

El País (2011), nota consultada, disponible en: http://elpais.com/diario/2011/07/09/catalunya/1310173643 850215.html) 
Fariña, J. (2014) Espacios videovigilados, en Blog de José Fariña Urbanismo, territorio y paisaje. Posteado en 21/07/2014, disponible en: https://elblogdefarina.blogspot.mx/2014/07/espacios-videovigilados.html

Felson, M. y R. Clarke. La ocasión hace al ladrón. Teoría de la prevención del delito. Nombre original: Oportunity makes thief. Practical theory for crime prevention. Publicado en Police Research Series, Paper 98, Home office, Policing and reducing crime Unit, Londres. Traducido por Maité Díaz i Pont y David Felip i Saborit. Consultado http://repositorio.gobiernolocal.es/xmlui/bitstream/handle/10873/855/claves06_09_felson_clarke.pdf

Fonseca, J.M. (2014) La importancia y la apropiación de los espacios públicos en las ciudades, publicado en Paakat Revista de Tecnología y Sociedad, "Cultura digital y las nuevas formas del erotismo". Año 4, núm. 7, septiembre 2014 - febrero 2015.

García, M. L. (sf) Propuesta de anteproyecto para la recuperación del sector 4, documento electrónico, Facultad de Arquitectura, Universidad Nacional Autónoma de México, disponible en http://www.ub.edu/multigen/donapla/espacio1.pdf

Gehl, J. (2006) La humanización de los Espacios Públicos. Reverte. Buenos Aires.

Gehl, J. (2014) Ciudades para la gente. Ediciones Infinito. Buenos Aires.

Gómez, C.P., (2008). Elementos para la construcción de políticas públicas de seguridad ciudadana, en Rivera V., F., (ed) (2008) Seguridad Multidimensional en América Latina. pp. 369-394, Quito: FLACSO Ecuador y Ministerio de Cultura del Ecuador.

González Ordovás, M.J. (2000) Políticas y estrategias urbanas: la distribución del espacio privado y público en la ciudad, Editorial Fundamentos Madrid.

González, P., (2003). Seguridad ciudadana. Cuadernos de Seguridad y defensa, Ciudad de Guatemala: FLACSO Guatemala.

Hernando, F. (2007) Estudio de los barrio preexistentes y emergentes: la trama urbana y su relación con la seguridad. Consideraciones prácticas sobre el urbanismo y la inseguridad. Publicado en "Ciudades, Urbanismo y Ciudad", Ayuntamiento de Madrid. Consultado en: www.madrid.es/UnidadWeb/Contenidos/Publicaciones/TemaEmergencias/PonenciasCongresoCiudades/Fic heros/Parte2.1.pdf

Hernando, F. (2008) La seguridad en las ciudades: el nuevo enfoque de la geoprevención. X Coloquio internacional de geocrítica, Universidad de Barcelona.

http://www.archdaily.mx/mx/02-340597/parque-ecologico-linea-verde-el-caso-de-reconversion-urbana-deaguascalientes-en-mexico

http://www.planjuarez.org/index.php/quienes-somos/el-juarez-que-queremos

Huizar, J. (2015). Informe del cuarto trimestre sobre incidencia delictiva en el Estado de México, Instituto de Estudios Legislativos de la Cámara de Diputados del Estado de México, Toluca. Consultado en octubre 15, 2016. Recuperado

http://www.inesle.gob.mx/INVESTIGACIONES/PDF/investigaciones2015/Incidencia\%20Delictiva\%20en\%20 el\%20Estado\%20de\%20Mexic0\%20Ultimo\%20trimestre.pdf

Idrovo, M. y Garcia-Almirall, P (2013), Convivencia y seguridad: estrategias de intervención urbana en el espacio público de barrios segregados y en conflicto. Caso de estudio: barrio la mina, ACE, Barcelona.

Jacobs, J. (1961) Muerte y vida de las grandes ciudades. Capitán Swing Libros. $2^{\mathrm{a}}$ Edición, 2011. Madrid.

Jacobs, J., (1961). Muerte y vida de las grandes ciudades., $2^{\text {a }}$ Edición, 2011. Madrid, España: Capitán Swing Libros.

Knoepfel, P. Larrue, C. Y Varone, F. (2012) Analisis y gestión de las políticas publicas, Ariel, Madrid.

Knoepfel, P. Larrue, C., Varone, F. y Hinojosa, M., (2007) Hacia un modelo de análisis de políticas públicas operativo. Un enfoque basado en los actores, sus recursos y las instituciones, publicado en Revista Ciencia Política, Volumen 2, (Número 3), pp. 10-42, DOI: https://doi.org/10.15446/cp

Kraft, M. y Furlong, S. (2006): Public Policy: Politics, Analysis and Alternatives, 2a ed., CQ Press, Washington, DC.

López de Lucio, R. (1993). Ciudad y urbanismo a finales del siglo XX. Valencia: Universitat de Valencia. 
López, M. y Arévalo, N. ( ), Patio Bellavista, disponible en http://www.plataformaurbana.cl/archive/2007/11/17/diseno-urbano-y-la-calidad-del-espacio-publico-en-chilepatio-bellavista/

Lynch, K. (1998). La imagen de la ciudad. Barcelona: Gustavo Gilly.

Macromural de Pachuca, disponible en https://es.wikipedia.org/wiki/Macromural de Pachuca y en http://viamexico.mx/palmitas-pachuca-mural-mexico/

Maggiolo, I; y Perozo, J. (2007) Políticas públicas: proceso de concertación Estado-Sociedad, en Revista Venezolana de Gerencia, Universidad del Zulia, vol. 12, (número 39), pp. 373-392.

Mathivet, C. (2009) El derecho a la ciudad: claves para entender la propuesta de crear "Otra ciudad posible", consultado en http://base.d-p-h.info/es/fiches/dph/fiche-dph-8034.html

Mazzanti, G., Bravo, M. (2016) La construcción inacabada: el rol del espacio público. Blog Planur-e Territorio, Paisaje, Urbanismo, Sostenibilidad y Diseño Urbano, invierno de 2016, disponible en: http://www.planure.es/articulos/ver/la-construcci-n-inacabada-el-rol-del-espacio-p-blico/completo

México Evalúa, Centro de Análisis de Políticas Públicas, (2014). Prevención del delito en México. ¿Dónde quedó la evidencia?. Recuperado de http://www.mexicoevalua.org/wp-content/uploads/2014/01/MEXEVA INDX-PREVDEL-LOW.pdf

ONU-Habitat (2004) Carta Mundial de Derecho a la Ciudad. Foro Social de las Américas, Quito. Foro Mundial Barcelona, Quito. Consultado en:

http://www.onuhabitat.org/index.php?option=com docman\&task=doc details\&gid=50\&ltemid=3

ONU-Habitat (2007). Por Ciudades más Seguras. ONU.

Plan Estratégico de Juárez, A.C. en http://www.planjuarez.org/index.php/quienes-somos/el-juarez-quequeremos/1579-6-recuperacion-del-patrimonio-historico-de-la-ciudad

Ramírez-Kuri, P. (2009). Espacio público y ciudadanía en la Ciudad de México. México: UNAM-IIS.

Rau Vargas et al (2008). Prevención de la violencia y el delito mediante el diseño ambiental en Latinoamérica y El Caribe: estrategias urbanas de cohesión social e integración ciudadana Revista INVI, Vol. 23, Núm. 64. Universidad de Chile. [Disponible en: http://revistainvi.uchile.cl/index.php/INVI/article/view/451/960].

Rau, M. y Castillo, P. (2008), Prevención de la violencia y el delito mediante el diseño ambiental en Latinoamérica y El Caribe: Estrategias urbanas de cohesión social e integración ciudadana, publicado en Revista INVI, No. 64, Noviembre, 2008 / Volumen No 23: 169-189.

Ríos, L.D., Rojas, J. (2012) Prácticas sociales en el espacio público. Usos que sobrepasan las normas sociales y el diseño del espacio. Publicado en Revista de Estudios Urbanos y Ciencias Sociales, vol II, número 1, 33-50. Disponible en: http://www2.ual.es/urbs/index.php/urbs/article/view/rios rojas/217

Roth, Andre-Noel (2002) Políticas públicas: formulación, implementación y evaluación,

Salazar, C., (2012), La definición de Política Pública, en Revista Bien común, Vol. 18 Junio-Julio, (Número 209), México, pp: 47-52.

Sánchez de Madariaga, I. (2008) Esquinas Inteligentes: la ciudad y el urbanismo moderno. Madrid. Alianza Editorial

Sánchez, J.M. (2014) Uso social del espacio público abierto: funciones y dimensiones, Blog Apúntate Una. Ideas para la dinamización sociocultural. Posteado el 12/06/2014, disponible en http://apuntateuna.es/usosocial-espacio-publico/

Selmini, Rossella (2009). La prevención: estrategias, modelos y definiciones en el contexto europeo. FLACSO-Quito.

Sozzo, M., (2000). Seguridad urbana y tácticas de prevención del delito. Cuadernos de Jurisprudencia y Doctrina Penal, Número $10 . \quad$ Buenos Aires. Recuperado de: http://www.alfonsozambrano.com/doctrina_penal/231011/dp-seguridad_urbana.pdf

Superislas en Barcelona, el nuevo modelo de espacio público en la ciudad, disponible en http://www.arquine.com/superislas-en-barcelona-el-nuevo-modelo-de-espacio-publico-de-la-ciudad/

Tudela P. (2005). Conceptos y orientaciones para políticas de seguridad ciudadana, Centro de Investigación y desarrollo policial, Policía de investigaciones de Chile, Santiago. 
Universidad Nacional Autónoma de México (2017), Proyecto Pro-Región, diagnóstico integral participativo para el municipio de Toluca, México.

Verdaguer, C. (2005) Evaluación del Espacio Público. Trabajo de investigación de doctorado. Escuela técnica Superior de Arquitectura de Madrid. Consultado http://www.gea21.com/ media/equipo/cv/evaluacion espacio publico indicadores ecocity dea c verdague $\underline{\text { r.pdf }}$

\section{Planes, políticas y programas}

Plan Nacional de Desarrollo, 2007-2012, en www.pnd.calderon.presidencia.gob.mx/

Plan Nacional de Desarrollo, 2013-2018, en www.presidencia.gob.mx

Programa Nacional de Prevención Social de la Violencia y la Delincuencia 2014-2018, www.dof.gob.mx/nota_detalle.php?codigo $=5343087$.

Plan de Desarrollo del Estado de México, 2011-2017, en edomex.gob.mx/plan_desarrollo_estado_mexico

Plan Municipal de Desarrollo de Toluca, 2013-2015, en
www.ipomex.org.mx/ipo/archivos/downloadAttach/528811.web

Plan Municipal de Desarrollo de Toluca, 2016-2018,

187.174.218.158/.../Plan\%20de\%20Desarrollo\%20Municipal\%20de\%20Toluca\%20201...

Plan Estatal de Desarrollo Urbano del Estado de México, 2008, en sedur.edomex.gob.mx/plan_estatal_de_desarrollo_urbano

Plan Municipal de Desarrollo Urbano, 2013, en seduv.edomexico.gob.mx/planes_municipales/Toluca/PMDUtol.pdf 